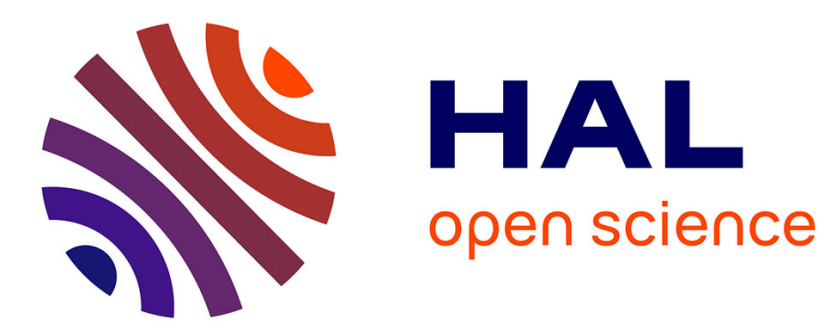

\title{
Nickel-Doped Sodium Cobaltite 2D Nanomaterials: Synthesis and Electrocatalytic Properties
}

\author{
Alberto Azor, Maria Luisa Ruiz-Gonzalez, Francisco Gonell, Christel \\ Laberty-Robert, Marina Parras, Clément Sanchez, David Portehault, José M \\ González-Calbet
}

\section{To cite this version:}

Alberto Azor, Maria Luisa Ruiz-Gonzalez, Francisco Gonell, Christel Laberty-Robert, Marina Parras, et al.. Nickel-Doped Sodium Cobaltite 2D Nanomaterials: Synthesis and Electrocatalytic Properties. Chemistry of Materials, 2018, 30 (15), pp.4986-4994. 10.1021/acs.chemmater.8b01146 . hal02129215

\section{HAL Id: hal-02129215 \\ https://hal.science/hal-02129215}

Submitted on 29 Jun 2019

HAL is a multi-disciplinary open access archive for the deposit and dissemination of scientific research documents, whether they are published or not. The documents may come from teaching and research institutions in France or abroad, or from public or private research centers.
L'archive ouverte pluridisciplinaire HAL, est destinée au dépôt et à la diffusion de documents scientifiques de niveau recherche, publiés ou non, émanant des établissements d'enseignement et de recherche français ou étrangers, des laboratoires publics ou privés. 


\section{Nickel-Doped Sodium Cobaltite 2D Nanomaterials: Synthesis and Electrocatalytic Properties}

Alberto Azor ${ }^{1}$, Maria Luisa Ruiz-Gonzalez ${ }^{1}$, Francisco Gonell ${ }^{2}$, Christel LabertyRobert $^{2}$, Marina Parras ${ }^{1}$, Clément Sanchez ${ }^{2}$, David Portehault ${ }^{2, *}$, José M. GonzálezCalbet $^{1, *}$

${ }^{1}$ Departamento de Química Inorgánica, Facultad de Químicas, Universidad Complutense, 28040-Madrid, Spain

${ }^{2}$ Sorbonne Université, CNRS, Collège de France, PSL Research University, Laboratoire de Chimie de la Matière Condensée de Paris (CMCP), 4 place Jussieu, F-75005, Paris, France

* Corresponding authors 


\section{ABSTRACT}

In this work we report a synthetic pathway to two-dimensional nanostructures of high oxidation state lamellar cobalt oxides with thicknesses of only few atom layers, through the combined use of precipitation in basic water at room temperature and gentle solid state topotactic transformation at $120{ }^{\circ} \mathrm{C}$. The $2 \mathrm{D}$ nanomaterials are characterized by X-ray diffraction, nitrogen porosimetry, scanning electron microscopy, transmission electron microscopy and especially scanning transmission electron microscopy coupled to energy dispersive X-ray analysis and electron energy loss spectroscopy to assess the composition of the nanosheets and oxidation state of the transition metal species. We show that the nanosheets preserve high oxidation states $\mathrm{Co}^{3+}$ and $\mathrm{Co}^{4+}$ of high interest for electrocatalysis of the Oxygen Evolution Reaction (OER). By combining high Co oxidation state, surface-to-volume ratio and optimized nickel substitution, the 2D nanomaterials produced in a simple way exhibit high OER electrocatalytic activity and stability in alkaline aqueous electrolyte comparable to standard materials obtained in harsh thermal conditions.

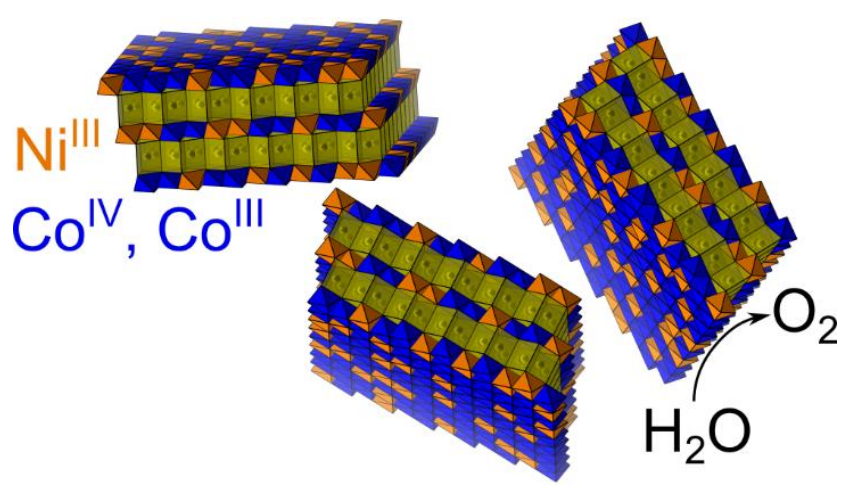




\section{INTRODUCTION}

Two-dimensional (2D) transition metal oxides exhibit a realm of properties different from their bulk counter parts and are of interest for electronics, catalysis, information storage and energy harnessing. ${ }^{1,2}$ Many of these 2D nanostructures arise from oxides exhibiting a layered structure that can be scaled down to only few atomic layers, by chemical exfoliation or by surface deposition. ${ }^{2}$ Among this latter family of solids, lamellar cobalt oxides $\mathrm{A}_{\mathrm{x}} \mathrm{CoO}_{2}$ (with $\mathrm{A}$ an alkali ion) possess a robust 2D structure derived from the Delafossite structural type (Figure 1), which can be described as sheets of edge-sharing $\mathrm{CoO}_{6}$ octahedra interleaved by alkali ions. ${ }^{3}$

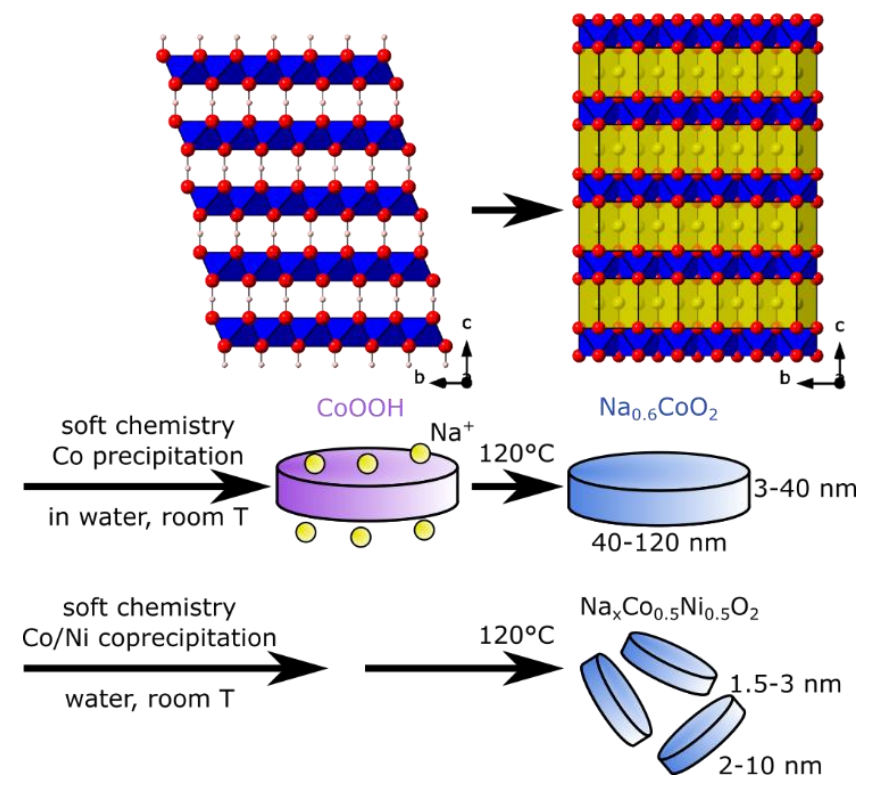

Figure 1. Crystal structures of cobalt oxyhydroxide $\mathrm{CoOOH}$ and three-layer $\mathrm{Na}_{\mathrm{x}} \mathrm{CoO}_{2}$ cobaltite (P3 structure). Sodium: yellow, cobalt: blue, oxygen: red, hydrogen: white. The coordination of alkali ions in the $\mathrm{P} 3 \mathrm{Na}_{\mathrm{x}} \mathrm{CoO}_{2}$ structure is trigonal prismatic. ${ }^{3}$ Schematics of the soft chemistry pathway employed in the present work toward nanoplatelets and nanoflakes of cobaltite and Ni-substituted cobaltite, respectively.

This structural arrangement allows a high ion mobility and good stability upon ion insertion and deinsertion. These features have boosted the lithiated phases as the most common cathode material in industrially developed lithium-ion batteries, ${ }^{4-6}$ which in turn have strongly motivated studies of sodium-intercalated $\mathrm{Na}_{x} \mathrm{CoO}_{2}$ as cathode for 
Na-ion batteries. $^{7,8}$ Besides electrochemical storage performances, the degree of occupation of the $\mathrm{Na}$ layer controls the charge in the $\mathrm{CoO}_{2}$ planes, giving rise to different properties as a function of $x$. Especially, the two-layer form of $\mathrm{Na}_{x} \mathrm{CoO}_{2}$ has been of significant recent interest, as it displays a variety of functional properties, including superconductivity $\left(\mathrm{T}_{\mathrm{C}}=4.5 \mathrm{~K}\right)$ in the hydrated phase $(x=0.3),{ }^{9}$ as well as thermoelectric energy conversion with a large thermopower $(100 \mu \mathrm{V} / \mathrm{K}$ at $300 \mathrm{~K}$ for $\gamma$ $\left.\mathrm{Na}_{0.5} \mathrm{CoO}_{2}\right) .{ }^{10}$ The three-layer $\beta-\mathrm{Na}_{0.6} \mathrm{CoO}_{2}$ phase has also been scrutinized, especially as conductive additive for nickel-metal hydride batteries ${ }^{11}$ with improved cycling stability.

2D nanostructures of $\mathrm{Na}_{\mathrm{x}} \mathrm{CoO}_{2}$ should exhibit enhanced properties related to the increase in the surface-to-volume ratio. For instance, nanostructuration should improve thermoelectric energy conversion by reducing thermal conductivity through phonon scattering at the grain-boundaries while maintaining a high electron mobility and large thermopower. ${ }^{12,13}$ Catalytic properties should as well be enhanced. This is especially true for electrocatalysis of the Oxygen Evolution Reaction (OER) occurring at the anode of (phot)electrochemical water splitting devices and metal-air batteries in charge operation. Cobalt-based materials are well-known OER electrocatalysts in alkaline media and large efforts are devoted since few years to understand and improve their activity and stability. ${ }^{14-20}$ Besides perovskite ${ }^{14,15}$ - and spinel ${ }^{16,17}$-derived cobaltites, lamellar cobalt(III) oxyhydroxide $\mathrm{CoOOH}$ has been intensively studied. ${ }^{18-20}$ In most cases, $\mathrm{Co}^{4+}$ sites are formed during the electrochemical conditions of OER and act as active electrocatalytic species. ${ }^{19}$ Hence, incorporating $\mathrm{Co}^{4+}$ species in a controlled manner at the synthesis stage would be a step forward in tuning the electrocatalytic properties. The $\mathrm{Na}_{\mathrm{x}} \mathrm{CoO}_{2}$ family offers a nice opportunity to reach this level of control due to its ability to accommodate cation substitution, for instance $\mathrm{Ni}, \mathrm{Mn}$ or $\mathrm{Cr}^{21,22}$ 
Especially, nickel incorporation can improve the OER electrocatalytic activity of $\mathrm{CoOOH}$ due to enhanced adsorption of intermediate species in the OER process. ${ }^{19}$ These considerations have motivated our search for a reliable synthetic pathway towards transition metal-substituted sodium-cobaltites 2D nanostructures, more specifically nanosheets with a limited number of $\mathrm{CoO}_{2}$ layers.

The stacking of $\mathrm{CoO}_{2}$ layers in sodium cobaltites is driven by electrostatic interactions between the negative sheets and the alkali $\mathrm{Na}^{+}$cations intercalated. Therefore, as other similar cases like lepidocrocite-type layered titanates, ${ }^{23}$ protonated Ruddlesden-Popper phases ${ }^{24}$ or layered manganites, ${ }^{25}$ exfoliation may be possible. Mechanical and soft chemistry delamination methods applied to weakly Van der Waals bounded two-dimensional compounds ${ }^{26}$ are hardly translatable to electrostatically stabilized phases due to stronger cohesion between the layers. The usual delamination strategy for such intercalated compounds is based on consecutive intercalations with progressively larger species in order to decrease electrostatic interactions, until the structure is split apart forming a colloidal suspension. The procedure is the only one reported so far to exfoliate sodium cobaltites ${ }^{27}$ produced as bulk solids, ${ }^{28-30}$ and very recently manganese-substituted sodium cobaltites, ${ }^{31}$ but it resulted in a strong reduction of $\mathrm{Co}$ species and the formation of $\mathrm{CoO}$ nanosheets, thus leading to a loss of the electrocatalytically relevant $\mathrm{Co}^{4+} / \mathrm{Co}^{3+}$ couple. A direct synthesis where the individual particles obtained would be as thin as possible, close to single layers, would overcome time-consuming iterative method and, more important, maintain the high mean oxidation state of cobalt.

In this paper, we develop a soft chemistry pathway using water as solvent and solid state topotactic phase transformation, to obtain the thinnest possible layered sodium cobaltite particles. We demonstrate that this simple method allows cobalt 
substitution by nickel in order to further tune the electrochemical properties. The simple synthesis strategy yields nanoflakes of doped sodium nano-cobaltites as thin as 1.5$3.0 \mathrm{~nm}$ ( 2 to $5 \mathrm{CoO}_{2}$ layers), the thinnest reported up to now, as a result from both low temperature synthesis and structural destabilization by the dopant. These nanomaterials exhibit electrocatalytic activity comparable to standard materials, while they are obtained in simpler and milder conditions.

\section{EXPERIMENTAL PROCEDURES}

The synthesis strategy is based on a modified procedure from the previous work of Pétrissans et al. ${ }^{30}$ The general approach consists in two steps. First, $\mathrm{CoOOH}$ particles are produced in a highly concentrated $\mathrm{NaOH}$ aqueous solution. Second, the oxyhydroxide particles surrounded by $\mathrm{Na}^{+}$ions are gently heat-treated in order to complete exchange of protons by sodium cations ions. Based on the Pourbaix diagram of $\mathrm{Co},{ }^{32} \mathrm{Br}_{2}\left(\mathrm{E}^{0}=1.07 \mathrm{~V} / \mathrm{ESH}\right)$, a relatively strong oxidizing agent was chosen.

All reagents were $99.9 \%$ grade, commercially available at Aldrich chemicals and used as received. In a typical synthesis, $12 \mathrm{~g}$ of sodium hydroxide are dissolved in 50 $\mathrm{mL}$ of mili-Q water in a $250 \mathrm{~mL}$ three-neck flask under $\mathrm{O}_{2}$ atmosphere. A $6 \mathrm{M} \mathrm{NaOH}$ solution is obtained. The flask temperature is kept at room temperature, and $0.7 \mathrm{~mL}$ of $\mathrm{Br}_{2}(14 \mathrm{mmol})$ is added to the solution, which turns yellow. Immediately afterwards, 5 $\mathrm{mL}$ of a $(1-x) \mathrm{M} \mathrm{Co}\left(\mathrm{NO}_{3}\right)_{2} \cdot 6 \mathrm{H}_{2} \mathrm{O}$ and $x \mathrm{M} \mathrm{Ni}\left(\mathrm{NO}_{3}\right)_{2} \cdot 3 \mathrm{H}_{2} \mathrm{O}(x$ depending on the desired composition) solution is added dropwise over 10 min directly to the vortex created by vigorous stirring. A black precipitate is formed immediately, which is recovered after centrifugation using a Sigma $30 \mathrm{KS}$ centrifuge at $21000 \mathrm{rpm}$. The precipitate is treated at $120^{\circ} \mathrm{C}$ for $24 \mathrm{~h}$ under air, producing a black hygroscopic powder. This treatment promotes sodium migration to the interlayer region and subsequent exchange of $\mathrm{H}^{+}$by 
$\mathrm{Na}^{+}$. Afterwards, a washing step is performed with pure methanol to remove the remaining $\mathrm{NaOH}$ (solubility $s=30.8$ wt. $\%$ at $\left.25^{\circ} \mathrm{C}^{33}\right), \mathrm{NaBr}\left(s=15.0\right.$ wt. $\%$ at $25^{\circ} \mathrm{C}^{34}$ ) and $\mathrm{Na}_{2} \mathrm{CO}_{3}\left(s=0.3\right.$ wt. $\%$ at $\left.22{ }^{\circ} \mathrm{C}^{35}\right)$ side products of the oxidation process. Water is avoided as washing solvent because it would affect the nature of the resulting phase, leading to re-hydrated phases and decreasing the $\mathrm{Na}$ content in the final material.

Finally, a selective sedimentation process was carried out on some Nisubstituted samples. In a typical assay, $0.5 \mathrm{~g}$ of as prepared sample is dispersed in 30 $\mathrm{mL}$ of ethanol (99.99\%) and sonicated with a high intensity ultrasonic processor Branson Sonifier Sound Enclosure (time $=30 \mathrm{~min}$, pulse $=0.5 \mathrm{~s} / 0.4 \mathrm{~s}$ (on/off), temp. $=$ $60{ }^{\circ} \mathrm{C}$, ampl. $=40 \%$ ). Once the sonication is finished, the suspension is left for $30 \mathrm{~min}$. The supernatant containing the smallest particles is recovered, centrifuged at $21000 \mathrm{rpm}$ and dried at $45^{\circ} \mathrm{C}$ under air overnight. Bulk $\mathrm{Na}_{0.6} \mathrm{CoO}_{2}$ was prepared by reacting $\mathrm{Na}_{2} \mathrm{CO}_{3}$ and $\mathrm{Co}_{3} \mathrm{O}_{4}$ in $\mathrm{O}_{2}$ at $850{ }^{\circ} \mathrm{C}$ for $20 \mathrm{~h}$.

Powder X-ray diffraction was carried out on the various synthesized polycrystalline samples using a PANalytical X'PERT diffractometer $\left(\mathrm{Cu} \lambda\left(\mathrm{K}_{\alpha}\right)=\right.$ $1.5405 \AA$ A) equipped with a sealed Xenon detector and Bragg-Brentano geometry. The reference patterns were taken from the ICSD file 22285 and reference 3 for $\mathrm{CoOOH}$ and $\mathrm{Na}_{0.6} \mathrm{CoO}_{2}$, respectively. The average cation composition was determined by ICP-OES (Perkin Elmer Optima 3300DV). Particle size and morphology were determined on a JEOL JSM 7600F scanning electron microscope, using a graphite holder and "gentlebeam" mode. Transmission electron microscopy (TEM) has been performed on a JEOL JEM 3000F electron microscope operating at $300 \mathrm{kV}$ fitted with and Oxford Inca EDS spectrometer used for compositional analysis. Scanning TEM (STEM) has been performed on a probe-corrected aberration microscope JEOL JEM ARM200cF. The 
cobalt oxidation state was estimated by energy electron loss spectroscopy (EELS) in a QuantumGIF spectrometer attached to the ARM 200cF microscope.

For electrocatalysis assessment, a rotating disk electrode (RDE) was prepared by coating a glassy carbon (GC) disk electrode $\left(0.07 \mathrm{~cm}^{2}\right.$, Radiometer Analytical) previously polished with diamond paste $(1 \mu \mathrm{m}$, BAS inc.) followed by alumina paste (0.05 $\mu \mathrm{m}, \mathrm{BAS}$ inc.) to reach mirror grade. A conductive ink containing the catalyst was then coated over the substrate. This ink was prepared from the catalyst powder, Acetylene Black (AB, Alfa Aesar) $\left(99.9+\%, 75 \mathrm{~m}^{2} \cdot \mathrm{g}^{-1}\right)$ and Nafion-117 solution $(5 \%$ in aliphatic alcohol, Sigma-Aldrich). The acetylene black powder was previously treated in nitric acid, by dispersing $500 \mathrm{mg}$ of $\mathrm{AB}$ in a $50 \mathrm{~mL}$ of $\mathrm{HNO}_{3} 20 \%$ at $80{ }^{\circ} \mathrm{C}$ overnight under stirring, followed by centrifugation and washing with water and vacuum drying. The ink was prepared by dispersing $10 \mathrm{mg}$ of catalyst powder in $10 \mathrm{~mL}$ of ethanol (99\%), along with $10 \mathrm{mg}$ of treated $\mathrm{AB}$. The mixture was sonicated in a water bath for 2 hours. Then, the dispersion was cooled to room temperature and dispersed with a sonic horn for 5 minutes. $435 \mu \mathrm{L}$ of ion-exchanged Nafion solution $(5 \mathrm{wt}$. \% in aliphatic alcohols, Aldrich) was then added immediately. The ink was sonicated for another 5 min and remained stable and aggregate free for at least 1 week. After few minutes of horn sonicating in cool conditions, $2 \mu \mathrm{L}$ of the ink was deposited on the GC substrate. The film was dried in air for $1 \mathrm{~h}$. The prepared electrode consisted in a black film coated on the GC RDE with an oxide content of $27 \mu \mathrm{g} \cdot \mathrm{cm}^{-2}$ disk.

Electrochemical characterization. The freshly prepared electrode was characterized with a three-electrode setup, with the RDE as the working electrode, a Pt wire as counter electrode and a $\mathrm{Ag} / \mathrm{AgCl}$ electrode as reference. The setup was connected to a VPS Biologic potentiostat. Prior to electrochemical experiments, the working electrode was hydrated with the $0.1 \mathrm{M} \mathrm{KOH}$ electrolyte for $30 \mathrm{~min}$. All 
experiments were performed in $\mathrm{O}_{2}$ saturated electrolyte at scan rates of 20 and $100 \mathrm{mV} \cdot \mathrm{s}^{-1}$ with five cycles for linear sweep voltammetry. Each experiment was repeated 3 to 5 times to ensure reproducibility.

\section{RESULTS AND DISCUSSIONS}

Cobalt oxyhydroxide $(\mathrm{CoOOH})$ and alkali cobaltites are isostructural. The interlayer gap of the former is occupied by $\mathrm{H}^{+}$ions while the $\mathrm{CoO}_{2}$ layers are interleaved by $\mathrm{Na}^{+}$ in the cobaltites. Hence, our protocol proceeds by the formation of $\mathrm{CoOOH}$ nanosheets followed by topotactic transformation through proton exchange with sodium ions. Briefly, the synthesis method is a soft chemistry procedure relying on an aqueous reaction medium under controlled atmosphere. Gentle thermal treatment $\left(120{ }^{\circ} \mathrm{C}\right)$ in the solid state is performed afterwards to enable structural conversion.

The intermediate products at the different stages of the synthesis have been analysed by powder XRD. The results for a dopant-free assay using $\mathrm{Br}_{2}$ as oxidant are shown in Figure 2. The raw material, after thermal treatment at $120{ }^{\circ} \mathrm{C}$, shows three phases: the main phase that can be identified as $\mathrm{Na}_{0.6} \mathrm{CoO}_{2}$, and $\mathrm{NaBr}$ and $\mathrm{Na}_{2} \mathrm{CO}_{3}$ obtained as impurities (Figure 2a). All diffraction peaks of the main phase can be attributed to rhombohedral $\mathrm{Na}_{0.6} \mathrm{CoO}_{2}$ where sodium ions are in a trigonal prismatic environment in the interlayer space. After washing with methanol, every $\mathrm{NaBr}$ and $\mathrm{Na}_{2} \mathrm{CO}_{3}$ diffraction maxima disappeared (Figure $2 \mathbf{b}$ ). The composition is confirmed by the $\mathrm{Na} / \mathrm{Co}$ ratio evaluated by ICP-OES, leading to $\mathrm{Na}_{(0.6 \pm 0.02)} \mathrm{CoO}_{2}$. It is worth mentioning that a slight shift of the (003) peak to higher angles can be observed after washing. This effect is associated with possible leaching of $\mathrm{Na}^{+}$ions from the interlayer space. If the washing step is performed before the thermal treatment, $\mathrm{CoOOH}$ is obtained (Figure 2c). The width of the (003) reflexion hints at structural disorder and 
most probably partially substitution of protons by sodium ions. The thermal treatment in the presence of sodium ions is of prime importance to fully exchange protons and enable crystallization of the cobaltite. $\mathrm{CoOOH}$ is also made of sheets of edge-sharing $\mathrm{CoO}_{6}$ octahedra and differs from the targeted $\mathrm{Na}_{0.6} \mathrm{CoO}_{2}$ by the interlayer distance, which is $4.38 \AA$ and $5.49 \AA$ for $\mathrm{CoOOH}$ and $\mathrm{Na}_{0.6} \mathrm{CoO}_{2}$, respectively. Hence, a topotactic transformation occurs readily from the oxyhydroxide to the oxide. Some cobaltite XRD peaks are significantly broader than others, especially the (003) reflection around $16^{\circ}(2 \theta)$. Such a broadening suggests a $2 \mathrm{D}$ morphology with (001) $\mathrm{CoO}_{2}$ sheets as basal planes, as confirmed below by electron microscopy, and/or disorder, including cation deficiency, substitution in the interlayer space and stacking faults.

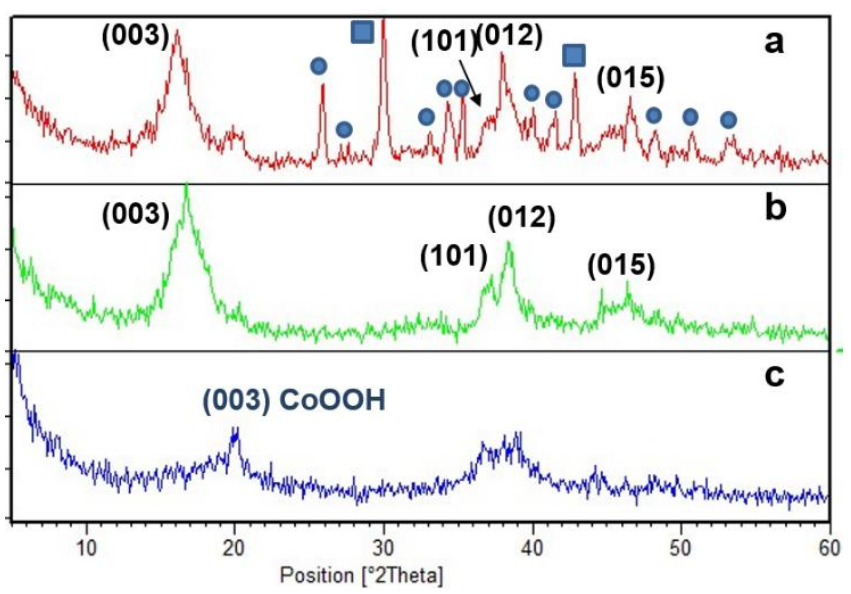

Figure 2. XRD patterns of $\mathrm{Na}_{0.6} \mathrm{CoO}_{2}$ samples: (a) as-prepared sample, (b) sample after washing with methanol and (c) sample washed before thermal treatment. In (a) and (b), (hkl) indexes correspond to $\mathrm{Na}_{0.6} \mathrm{CoO}_{2}$. Squares correspond to $\mathrm{NaBr}$ and circles correspond to $\mathrm{Na}_{2} \mathrm{CO}_{3}$. The indexes in (c) correspond to $\mathrm{CoOOH}$.

The synthesis conditions were adapted to yield transition metal-doped cobaltites. The procedure consists in adding the corresponding metal nitrate to the initial cobalt salt. The incorporation of $\mathrm{Cu}, \mathrm{Mn}$ and $\mathrm{Cr}$ was unsuccessful, leading to the segregation of $\mathrm{CuO}$ (tenorite), $\mathrm{Mn}(\mathrm{OH})_{2}$ and $\mathrm{Cr}_{2} \mathrm{O}_{3}$, respectively (not shown). On the opposite, no 
significant structural changes were detected for $\mathrm{Ni}$ substitutions below 50 at. \% (Figure SI.1). Therefore, the nickel atoms should be incorporated in the $\mathrm{Na}_{0.6} \mathrm{CoO}_{2}$ structure, constituting the $\mathrm{Na}_{x} \mathrm{Ni}_{y} \mathrm{Co}_{1-y} \mathrm{O}_{2}$ solid solution (with $y \leq 0.5$ ) (Table 1). While $y$ $=0.1$ and 0.2 compositions show XRD patterns similar to the undoped sample, for $y=$ 0.3, 0.4 and 0.5, a dramatic peak broadening is observed, which indicates decreasing of the particle size or increased strains along all crystallographic directions (Figure SI.1). For $\mathrm{Ni}$ contents higher than 50 at. $\%$ phase segregation appears. The average $\mathrm{Na}$ content, evaluated by ICP-OES and EDS, is similar to that of the undoped sample.

Table 1. Morphological characteristics, composition and oxidation states of the transition metal cations of some samples. The nanoflakes are obtained from the nanoplatelets/nanoflakes (number ratio 10/90) sample by selective sedimentation.

\begin{tabular}{|r|r|r|r|r|}
\hline $\begin{array}{r}\text { Nominal } \\
\text { composition }\end{array}$ & $\begin{array}{r}\text { Morphology } \\
(\mathrm{TEM})\end{array}$ & $\begin{array}{r}\text { Dimensions } \\
(\mathrm{nm})\end{array}$ & $\begin{array}{r}\text { Measured Ni/Co } \\
\text { composition (EDX) }\end{array}$ & $\begin{array}{r}\mathrm{Ni} \text { - Co } \\
\text { oxidation } \\
\text { states (from } \\
\text { EELS, } \\
\text { Table 2) }\end{array}$ \\
\hline $\mathrm{Na}_{0.6} \mathrm{CoO}_{2}$ & nanoplatelets & $40-120 * 3-40$ & & \\
& & & $\mathrm{Na}_{0.6} \mathrm{CoO}_{2}$ & $/$ - III/IV \\
\hline $\mathrm{Na}_{0.6} \mathrm{Ni}_{0.3} \mathrm{Co}_{0.7} \mathrm{O}_{2}$ & $\begin{array}{r}\text { nanoplatelets } \\
\text { nanoflakes }\end{array}$ & $\begin{array}{r}40-120 * 3-40 \\
2-10 * 1.5-3\end{array}$ & $\begin{array}{r}\mathrm{Na}_{0.6} \mathrm{Ni}_{0.12 \pm 0.07} \mathrm{Co}_{0.88 \pm 0.07} \mathrm{O}_{2} \\
\mathrm{Na}_{0.6} \mathrm{Ni}_{0.30 \pm 0.05} \mathrm{Co}_{0.70 \pm 0.05} \mathrm{O}_{2}\end{array}$ & III - III/IV \\
\hline $\mathrm{Na}_{0.6} \mathrm{Ni}_{0.5} \mathrm{Co}_{0.5} \mathrm{O}_{2}$ & nanoplatelets & $40-120 * 3-40$ & $\mathrm{Na}_{0.6} \mathrm{Ni}_{0.05 \pm 0.03} \mathrm{Co}_{0.95 \pm 0.03} \mathrm{O}_{2}$ & III - III/IV \\
& nanoflakes & $2-10 * 1.5-3$ & $\mathrm{Na}_{0.6} \mathrm{Ni}_{0.32 \pm 0.03} \mathrm{Co}_{0.68 \pm 0.03} \mathrm{O}_{2}$ & \\
\hline $\mathrm{Na}_{0.6} \mathrm{Ni}_{0.5} \mathrm{Co}_{0.5} \mathrm{O}_{2}$ & nanoflakes & $2-10 * 1.5-3$ & $\mathrm{Na}_{0.6} \mathrm{Ni}_{0.50 \pm 0.03} \mathrm{Co}_{0.50 \pm 0.03} \mathrm{O}_{2}$ & III - III/IV \\
\hline
\end{tabular}

The lamellar morphology of $\mathrm{Na}_{0.6} \mathrm{CoO}_{2}$ and $\mathrm{Ni}$-doped samples has been evidenced by SEM and TEM. SEM (Figure 3a) and TEM (Figure 3b) show that the undoped $\mathrm{Na}_{0.6} \mathrm{CoO}_{2}$ compound is obtained as hexagonal nanoplatelets of $40-120 \mathrm{~nm}$ basal face and 3-40 nm thickness. In contrast, the addition of nickel provokes a dramatic particle size reduction in all directions, in agreement with XRD. Actually, the TEM image (Figure 3c) for a sample with nominal composition $\mathrm{Na}_{0.6} \mathrm{Co}_{0.5} \mathrm{Ni}_{0.5} \mathrm{O}_{2}$ shows 
agglomerated nanoflakes with basal faces around $5 \mathrm{~nm}$. The thickness and structural features of such nanoflakes have been assessed by further HRTEM studies (Figure 4).

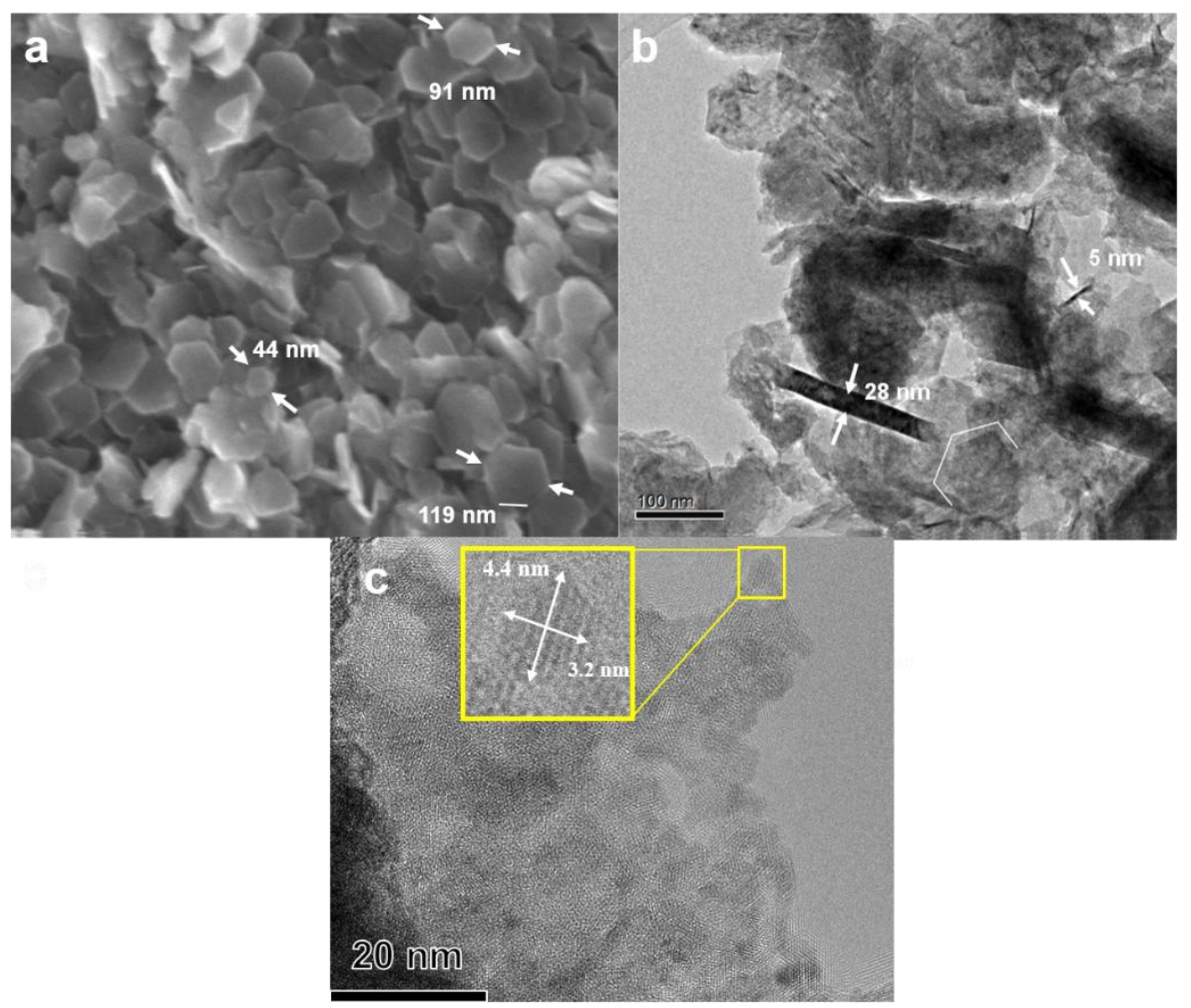

Figure 3. Electron micrographs of the $\mathrm{Na}_{0.6} \mathrm{CoO}_{2}$ sample: (a) SEM and (b) TEM low magnification image evidencing two different orientations of the nano-platelets in the sample: the basal face and the edge. (c) TEM micrograph of a $\mathrm{Na}_{0.6} \mathrm{Co}_{0.5} \mathrm{Ni}_{0.5} \mathrm{O}_{2}$ sample showing in the inset a high resolution magnification of an individual nanoflake.

HRTEM shows that the particles are crystalline, either in the undoped (Figure SI.2) and doped samples $\left(\mathrm{Na}_{0.6} \mathrm{Ni}_{0.3} \mathrm{Co}_{0.7} \mathrm{O}_{2}\right.$ in Figure 4, similar results for $\left.\mathrm{Na}_{0.6} \mathrm{Ni}_{0.5} \mathrm{Co}_{0.5} \mathrm{O}_{2}\right)$. The projections along the basal and lateral faces can be indexed along the [001] (Figures 4a) and [100] (Figures 4b) zone axes, respectively, of the parent rhombohedral cell of the lamellar $\mathrm{Na}_{0.6} \mathrm{CoO}_{2}$ structure, in good agreement with XRD and ICP analysis. Schematic representations of both projections are inserted in Figures $4 \mathbf{a}$ and $4 \mathbf{b}$. The 2 to $10 \mathrm{~nm}$ flakes have a thickness of $1.5-3 \mathrm{~nm}$ and are 
aggregated, forming a matrix where the particles are rotated in respect to each other, as confirmed by the diffuse Fast Fourier Transform (FFT) corresponding to the whole area (marked as A). The presence of only a few layers is a remarkable feature of the synthesized materials supporting the success of delamination. Overall, four-layered nanosheets of Ni-substituted cobaltites are predominant (Figure 3-4). Sheets with even fewer numbers of layers are present (see Figure SI.3). This situation, as well as presence of severe distortion and bending of the layers, hinders unravelling the actual three-layer derived $\mathrm{Na}_{0.6} \mathrm{CoO}_{2}$ structure. ${ }^{3}$ It is also worth mentioning that as the $\mathrm{Ni}$ content increases, the proportion of the smaller particles oriented along the [001] zone axis increases in relation to those along [100] due to the diminished aspect ratio.
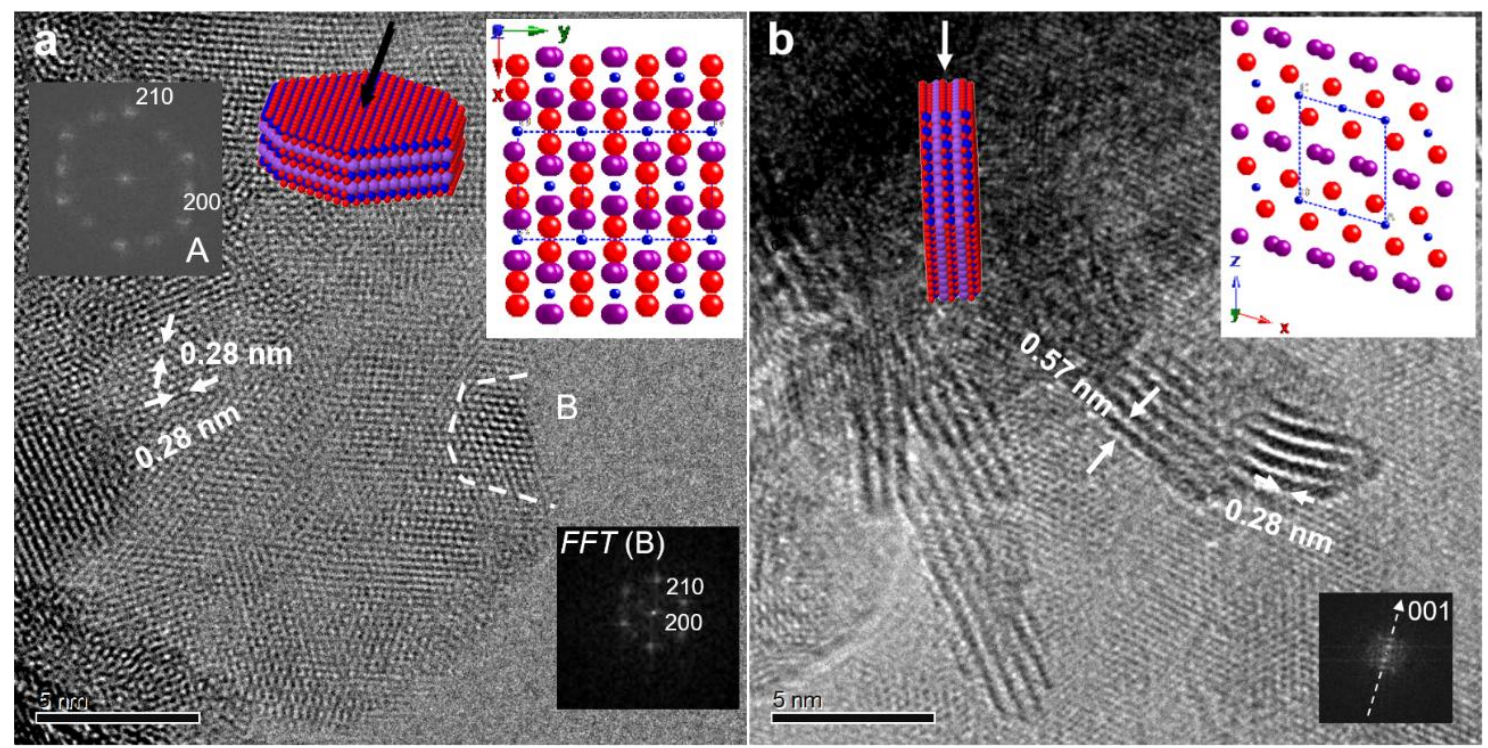

Figure 4. HRTEM images of a sample $\mathrm{Na}_{0.6} \mathrm{Ni}_{0.3} \mathrm{Co}_{0.7} \mathrm{O}_{2}$ : small nanoflakes orientated along two directions. (a) The [001] projection (zone axis). Notice that due to insufficient thickness, nanoflakes boundaries cannot be observed. (b) The [100] projection (zone axis) of the lamellar $\mathrm{Na}_{\mathrm{x}} \mathrm{CoO}_{2}$ system.

A local EDS study reveals different Ni concentrations depending on the particle size, as shown in Table 1: the smallest nano-objects, so-called nanoflakes, are enriched in Ni compared to bigger nanoplatelets. For each overall composition, the Ni content 
incorporated in the nanoflakes) remains constant, close to 0.5 per unit formula. The larger particles present lower $\mathrm{Ni}$ content between 0.05 and 0.13 . This means that nickel uptake promotes smaller particle sizes, while the cobalt excess is accommodated in less doped larger nanoplatelets.

With the goal of getting information about the local atomic distribution as well as the Co and Ni oxidation states, a STEM study in an aberration-corrected microscope was performed with both High Angle Annular Dark Field (HAADF), and Annular Bright field (ABF) detectors, sensitive to heavy and light elements, respectively. This study was combined with Electron Energy Loss Spectroscopy (EELS) (see details in SI.A). The STEM study performed on nanoflakes evidences their lability under the electron beam even at low acceleration voltages $(80 \mathrm{KV})$. HAADF images could be obtained (see Figure SI.4) but it was impossible to acquire the corresponding EELS spectrum images. Nevertheless the larger nanoplatelets were slightly more stable as shown in Figure 5 which displays characteristic HAADF and ABF images of nanoplatelets along the [100] zone axis of a $\mathrm{Na}_{0.6} \mathrm{Ni}_{0.3} \mathrm{Co}_{0.7} \mathrm{O}_{2}$ sample (corresponding low magnification images showing the elongated morphologies are shown as insets). It should be noticed that the nanoflakes are highly unstable under the electron probe. Therefore, the STEM study was mainly performed on medium-size particles, so called nanoplatelets. The Z-contrast HAADF image (Figure 5a) reveals bright atomic columns corresponding to $\mathrm{Co}$ and $\mathrm{Ni}$. No evidence of transition metal cation migration in the interlayer space was obtained. The crystallographic distances can be indexed according to the $\mathrm{R} \overline{3} \mathrm{~m}$ cell of $\mathrm{Na}_{0.6} \mathrm{CoO}_{2}$ with periodicities along $b, 0.28 \mathrm{~nm}$, and $c, 16.44 \mathrm{~nm}$. On 
the other hand, since $\mathrm{Co}(\mathrm{Z}=27)$ and $\mathrm{Ni}(\mathrm{Z}=28)$ only differ in one unit of atomic number no contrast differences can be observed. In order to get information about oxygen and sodium distributions, the $\mathrm{ABF}$ image was simultaneously acquired. $\mathrm{ABF}$ imaging in STEM has been established as a robust method for observing light atoms like oxygen, lithium or hydrogen. ${ }^{36,37}$ The corresponding ABF image (Figure 5b) evidences the introduction of $\mathrm{Na}$ in the interlayer space between the $\mathrm{Co}_{1-\mathrm{x}} \mathrm{Ni}_{\mathrm{x}} \mathrm{O}_{2}$ sheets. It can be better observed on the magnified image Figure 5c on which the crystallographic structure is superimposed. The apparent low quality of the HAADF and ABF images is due to the extremely high instability of the sample under the electron beam even at low voltages $(80 \mathrm{kV})$.
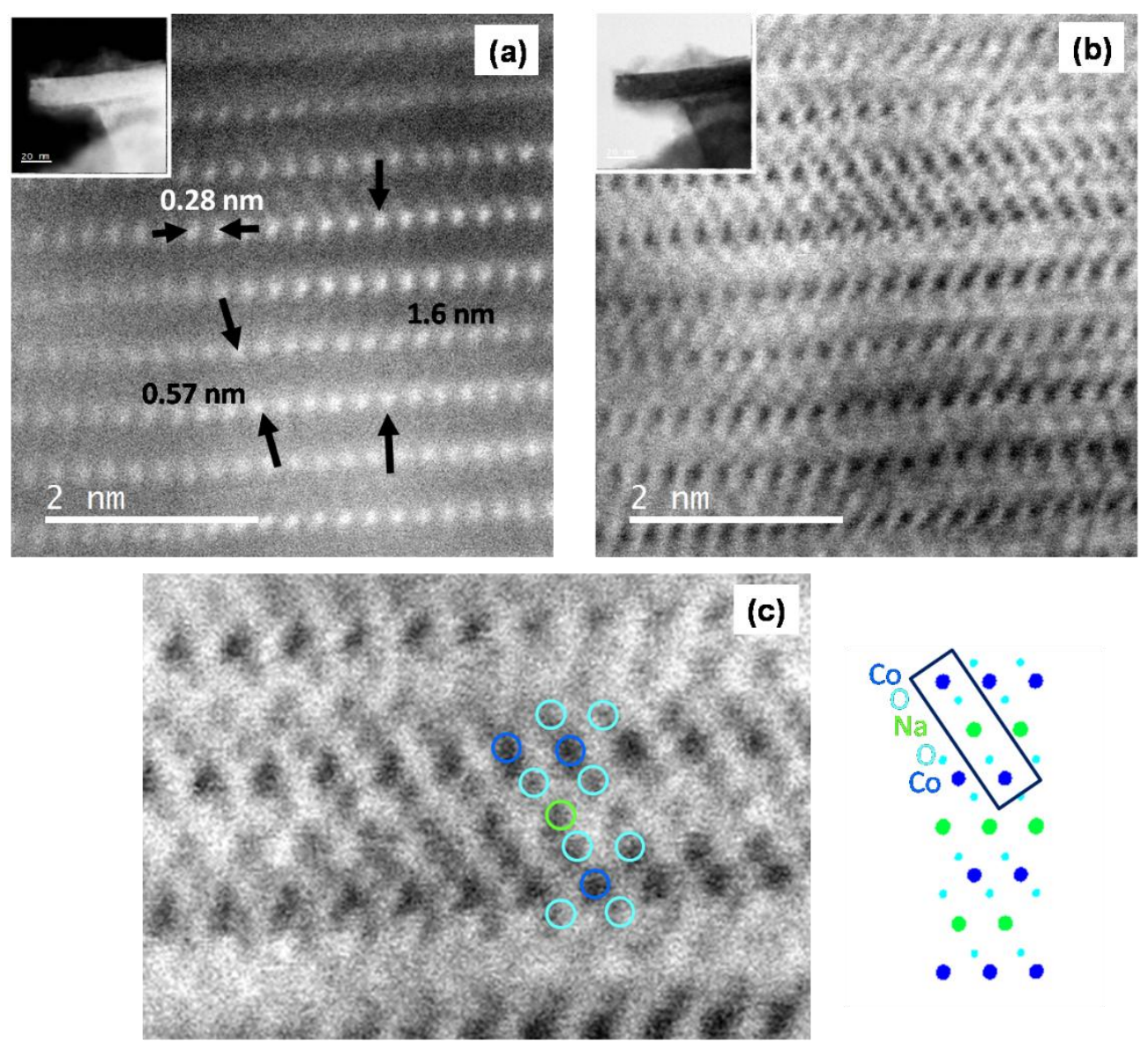
Figure 5. Characteristic atomically resolved STEM images of a nanoplatelet in a sample $\mathrm{Na}_{0.6} \mathrm{Ni}_{0.3} \mathrm{Co}_{0.7} \mathrm{O}_{2}$ with (a) HAADF and (b) $\mathrm{ABF}$ detections. (c) Magnified STEM-ABF image with a schematic representation of the atom distribution along this [100] projection.

Atomically resolved EELS chemical maps (see SI.A) were also obtained (Figure 6). Figure 6a shows the HAADF image and the area selected for the EELS study (highlighted in green). The image simultaneously acquired with the spectra and the corresponding sum spectrum are displayed in Figure $\mathbf{6 b}$ and $\mathbf{6 c}$, respectively. This spectrum confirms the presence of $\mathrm{Na}, \mathrm{Ni}, \mathrm{Co}$ and $\mathrm{O}$. The corresponding chemical maps are depicted in Figure d-g. In spite of the relatively low quality of these maps due to the sample damage, they suggest that $\mathrm{Ni}$ is substituting Co cations.
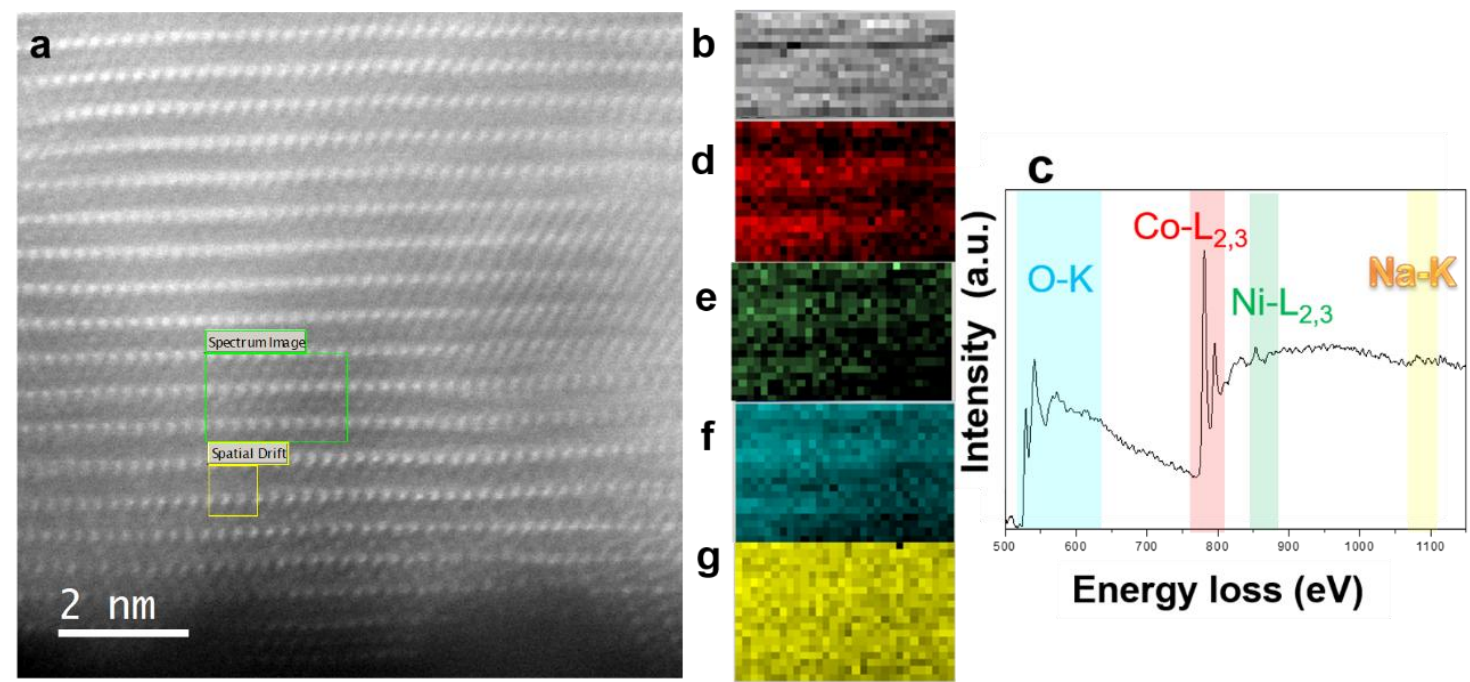

Figure 6. (a) HAADF detail of a $\mathrm{Na}_{0.6} \mathrm{Ni}_{0.3} \mathrm{Co}_{0.7} \mathrm{O}_{2}$ nanoplatelets. (b) Simultaneously acquired image. (c) Sum spectrum. (d-g) Chemical maps obtained in the green square in (a) from the $\mathrm{Co}-\mathrm{L}_{2,3}, \mathrm{Ni}-\mathrm{L}_{2,3}, \mathrm{O}-\mathrm{K}$ and $\mathrm{Na}-\mathrm{K}$ edges, respectively.

An EELS study of the $\mathrm{Co}$ and $\mathrm{Ni}$ oxidation state on $\mathrm{Na}_{0.6} \mathrm{Co}_{0.7} \mathrm{Ni}_{0.3} \mathrm{O}_{2}$ and $\mathrm{Na}_{0.6} \mathrm{Co}_{0.5} \mathrm{Ni}_{0.5} \mathrm{O}_{2}$ nanoflakes was performed. (see details in SI.A). A representative sum spectrum acquired over a line of $2 \mathrm{~nm}$ on a $\mathrm{Na}_{0.6} \mathrm{Ni}_{0.5} \mathrm{Co}_{0.5} \mathrm{O}_{2}$ nanoflake is shown in Figure 7. The $\mathrm{O}-\mathrm{K}$, Co $\mathrm{L}_{2,3}$, Ni $\mathrm{L}_{2,3}$ and $\mathrm{Na}-\mathrm{K}$ edges are clearly seen. The Co and $\mathrm{Ni}$ oxidation states were qualitatively estimated by measuring the relative intensities of the 
$\mathrm{M}-\mathrm{L}_{2}$ and $\mathrm{M}-\mathrm{L}_{3}$ white lines. ${ }^{38}$ In order to minimize the error due to the spectra background signal, $\mathrm{I}\left(\mathrm{L}_{3} / \mathrm{L}_{2}\right)$ values were calculated using the amplitude value obtained from the fitting of the second derivative of the $\mathrm{M}-\mathrm{L}_{2,3}$ white lines to a Gaussian curve. The resulting Co $\mathrm{L}_{3} / \mathrm{L}_{2}$ ratio, measured on 15 different regions to verify reproducibility, was $2.6 \pm 0.1$ for $\mathrm{Na}_{0.6} \mathrm{Co}_{0.7} \mathrm{Ni}_{0.3} \mathrm{O}_{2}$ and $\mathrm{Na}_{0.6} \mathrm{Co}_{0.5} \mathrm{Ni}_{0.5} \mathrm{O}_{2}$ samples, $2.5 \pm 0.1$ for the undoped $\mathrm{Na}_{0.6} \mathrm{CoO}_{2}$ sample. These values have been compared to reference $\mathrm{L}_{3} / \mathrm{L}_{2}$ intensity ratios measured for $\mathrm{Co}(\mathrm{III})$ and $\mathrm{Co}(\mathrm{II})$ standards $\mathrm{LaCoO}_{3}$ and $\mathrm{CoO}$, respectively (see Table 2, SI.A and Figures SI.5), and reported for the Co(IV) standard $\mathrm{CoSi}_{2}$ by Wang et al. ${ }^{39,40}$ The values for the undoped and Ni-doped samples are between those of $\mathrm{Co}(\mathrm{III})$ and $\mathrm{Co}(\mathrm{IV})$, thus discarding the presence of $\mathrm{Co}(\mathrm{II})$ and showing mixed valence $\mathrm{Co}(\mathrm{IV}) / \mathrm{Co}(\mathrm{III})$ (Tables 1 and 2). In addition, the energy of the $\mathrm{Co}-\mathrm{L}_{2,3}$ edges for the undoped and $\mathrm{Ni}$-doped samples is located between those of $\mathrm{Co}(\mathrm{IV})\left(\mathrm{Ba}_{2} \mathrm{CoO}_{4}\right)$ and $\mathrm{Co}(\mathrm{III})\left(\mathrm{LaCoO}_{3}\right)$ references (Figure SI.5), hence supporting the conclusion from the $\mathrm{L}_{3} / \mathrm{L}_{2}$ intensity ratios of mixed valence $\mathrm{Co}(\mathrm{IV}) / \mathrm{Co}(\mathrm{III})$ with no $\mathrm{Co}(\mathrm{II})$. The comparison with a reference $\mathrm{Co}(\mathrm{IV}) / \mathrm{Co}$ (III) sample $\mathrm{La}_{0.7} \mathrm{Sr}_{0.3} \mathrm{CoO}_{3}$ (Figure SI.5) is in agreement with this statement. Moreover, the corresponding $\mathrm{Ni} \mathrm{L}_{3} / \mathrm{L}_{2}$ ratio was also evaluated at $3.1 \pm 0.1$ for the same region. Comparison with the standards for $\mathrm{Ni}(\mathrm{II})$ and Ni(III) (see Table 2 and SI.A) suggests that all nickel in the sample is Ni(III).

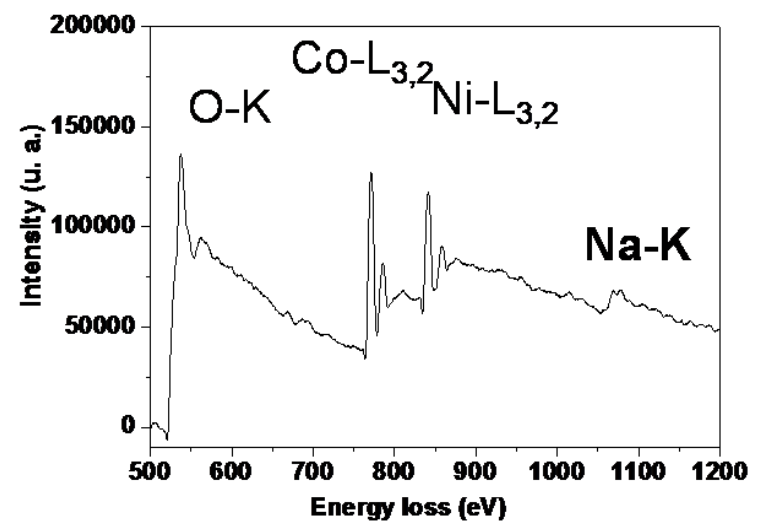


Figure 7. Representative EELS spectra for $\mathrm{Na}_{0.6} \mathrm{Ni}_{0.5} \mathrm{Co}_{0.5} \mathrm{O}_{2}$, showing the $\mathrm{O}-\mathrm{K}, \mathrm{Co}-\mathrm{L}_{3,2}$, $\mathrm{Ni}-\mathrm{L}_{3,2}$ and $\mathrm{Na}-\mathrm{K}$ edges.

Table 2. EELS intensities $I\left(\mathrm{~L}_{3} / \mathrm{L}_{2}\right)$ ratio and corresponding oxidation states for $\mathrm{Co}, \mathrm{Ni}$ references, and for the as-synthesized $\mathrm{Na}_{0.6} \mathrm{Ni}_{0.5} \mathrm{Co}_{0.5} \mathrm{O}_{2}$ sample. ${ }^{*}$ value taken from references ${ }^{39,40}$.

\begin{tabular}{|l|c|c|c|c|}
\hline & \multicolumn{2}{|c|}{$\mathrm{I}\left(\mathrm{L}_{3} / \mathrm{L}_{2}\right)$} & \multirow{2}{*}{$\begin{array}{c}\text { Co } \\
\text { oxidation } \\
\text { state }\end{array}$} & $\begin{array}{c}\text { Ni } \\
\text { oxidation } \\
\text { state }\end{array}$ \\
\cline { 2 - 4 } & $\mathrm{Co}$ & $\mathrm{Ni}$ & II & - \\
\hline $\mathrm{CoO}$ reference $(\mathrm{Co}(\mathrm{II}))$ & $4.4 \pm 0.1$ & - & III & - \\
\hline $\mathrm{LaCoO}_{3}$ reference $(\mathrm{Co}(\mathrm{III}))$ & $2.7 \pm 0.1$ & - & IV & - \\
\hline $\mathrm{CoSi}_{2} *$ reference $(\mathrm{Co}(\mathrm{IV}))$ & $2.1 \pm 0.1$ & - & - & II \\
\hline $\mathrm{NiO}$ reference $(\mathrm{Ni}(\mathrm{II}))$ & - & $4.7 \pm 0.1$ & - & III \\
\hline $\mathrm{NdNiO}_{3}$ reference $(\mathrm{Ni}(\mathrm{III}))$ & - & $3.1 \pm 0.1$ & III \\
\hline $\mathrm{Na}_{0.6} \mathrm{CoO}_{2}$ & $2.5 \pm 0.1$ & - & III/IV & III \\
\hline $\mathrm{Na}_{0.6} \mathrm{Ni}_{0.3} \mathrm{Co}_{0.7} \mathrm{O}_{2}$ & $2.6 \pm 0.1$ & $3.1 \pm 0.1$ & III/IV & III \\
\hline $\mathrm{Na}_{0.6} \mathrm{Ni}_{0.5} \mathrm{Co}_{0.5} \mathrm{O}_{2}$ & $2.6 \pm 0.1$ & $3.1 \pm 0.1$ & III/IV & \multicolumn{2}{|c}{} \\
\hline
\end{tabular}

On the basis of these results, it can be concluded that $\mathrm{Na}_{\mathrm{x}} \mathrm{Ni}_{\mathrm{y}} \mathrm{Co}_{1-\mathrm{y}} \mathrm{O}_{2}$ nanoflakes showing the delafossite structural type have been synthesized. What remains unexplained is why the particle size is so drastically reduced after Ni inclusion in the structure. The connexion between the $\mathrm{Ni}$ incorporation and particle size reduction is clear since the compositional analysis shows always Ni content differences in large and small particles. A possible explanation could be the incorporation of structural 
distortions by the presence of a foreign metal. Assuming high spin configuration for both transition metals, the corresponding ionic radius are $0.53 \AA$ for $\mathrm{Co}(\mathrm{IV}), 0.61 \AA$ for Co(III) and $0.60 \AA$ for Ni(III); all of them in octahedral coordination. ${ }^{41}$ Incorporation of $\mathrm{Ni}$ (III) in the octahedral layers results in larger mismatch between the cations and higher strains that might be exacerbated due to the Jahn Teller effect for $\mathrm{Ni}(\mathrm{III})$ in octahedral environment. Because of their high surface-to-volume ratio, especially at the edges, small nanoflakes are expected to stand higher structural strains than bigger particles, and then to accommodate larger amounts of nickel. Such a size decrease upon addition of foreign ions has also been observed in other systems, such as fluorides. ${ }^{42}$

Our synthetic approach enables incorporating $\mathrm{Co}^{4+}$ and $\mathrm{Ni}^{3+}$ species in octahedral environment into layered cobalt oxide materials before using the material for electrocatalysis. Such species are well-known to enhance electrocatalytic activity in the Oxygen Evolution Reaction (OER), especially $\mathrm{Co}^{4+}$ that are active sites for OER. ${ }^{16-19,43}$ Hence, the layered cobaltite nanostructures appear as designed materials prior to their implementation as OER electrodes in (photo)electrochemical water splitting devices or metal-air batteries, for instance. We have assessed the OER electrocatalytic properties of the as-synthesized nanostructured layered cobaltites with a three-electrode setup in an aqueous $0.1 \mathrm{~mol} \mathrm{~L}^{-1} \mathrm{KOH}$ solution and regular carbon black/Nafion/cobaltite particles composite electrodes deposited on glassy carbon as working electrode. Three nanostructured samples were analysed (Table 1): first, undoped 40-120 nm-wide and 340 nm-thick $\mathrm{Na}_{0.6} \mathrm{CoO}_{2}$ nanoplatelets; second, the $\mathrm{Na}_{0.6} \mathrm{Ni}_{0.5} \mathrm{Co}_{0.5} \mathrm{O}_{2}$ sample made of $10 \%$ of the nanoplatelets of the same dimensions and $90 \%$ of $2-10 \mathrm{~nm}$-wide, $3-5 \mathrm{CoO}_{2}$ layers-thick nanoflakes; third, these nanoflakes purified by sedimentation. Two additional reference samples were produced by solid state chemistry and assessed: bulk 
$\mathrm{Na}_{0.6} \mathrm{CoO}_{2}$ and bulk $\mathrm{Ba}_{0.5} \mathrm{Sr}_{0.5} \mathrm{Co}_{0.8} \mathrm{Fe}_{0.2} \mathrm{O}_{3-\delta}$ (BSCF). The latter compound is known to be highly electrocatalytically active for the OER. ${ }^{14}$

First, the material properties were assessed by linear sweep voltammetry (LSV). After 5 cycles (Figure 8) in the potential range 1.15-1.85 V/RHE at $20 \mathrm{mV} \mathrm{s}^{-1}$, the i-E curves of the three nanostructured samples reach higher current than bulk $\mathrm{Na}_{0.6} \mathrm{CoO}_{2}$, thus suggesting enhanced activity of the nanoscaled materials compared to the bulk. This was already the case at the first LSV cycle (Figure SI.6). A reversible oxidation event occurs for the Ni-containing samples at $1.3 \mathrm{~V} / \mathrm{RHE}$, which increases in intensity when the nanoflakes are purified. Hence, this behavior is characteristic of the nanoflakes that are enriched in Ni. According to the literature, ${ }^{17,43}$ it is attributed to the couple $\mathrm{Ni}(\mathrm{III}) / \mathrm{Ni}(\mathrm{II})$. The corresponding oxidation wave was also present in the first scan (Figure SI.6) but at higher potential 1.4 V/RHE, suggesting changes in the local environment of Ni during the first scan. Although Ni(II) was not detected by STEMEELS in the dry samples, it may appear when the materials are put in contact with the aqueous electrolyte, prior to voltammetric measurements. ${ }^{19}$ According to the recorded overpotentials (Table 3), the pure $\mathrm{Na}_{0.6} \mathrm{Ni}_{0.5} \mathrm{Co}_{0.5} \mathrm{O}_{2}$ nanoflakes are more active than the $\mathrm{Na}_{0.6} \mathrm{Ni}_{0.5} \mathrm{Co}_{0.5} \mathrm{O}_{2}$ nanoplatelets/nanoflakes mixture, so that activity is increased for larger surface-to-volume ratio and increased $\mathrm{Ni}$ content (Table 1). This behaviour is related to previous observations of similar enhancement of the OER activity in Co ${ }^{\text {III }}$ oxyhydroxide by doping with $\mathrm{Ni}$, due to the stabilisation of surface hydroxyl groups as intermediates in the OER process. ${ }^{19,20}$ At higher sweep rate $\left(100 \mathrm{mV} \mathrm{s}^{-1}\right.$, Figure SI.7), similar behaviors are observed. Tafel plot analyses at the fifth LSV cycle for $20 \mathrm{mV} \mathrm{s}^{-1}$ (Figure 8, Figure SI.8 and Table 3) yield for all the layered cobaltite samples slopes of ca. $30 \mathrm{mV} \cdot \mathrm{dec}^{-1}$. Such low values are in agreement with previously reported behaviors 
of Ni-doped cobalt oxides ${ }^{17,20}$ and suggest similar electrocatalytic mechanisms ${ }^{18,44}$ with high electrocatalytic activity of the nanoscaled Ni-doped layered cobaltites.

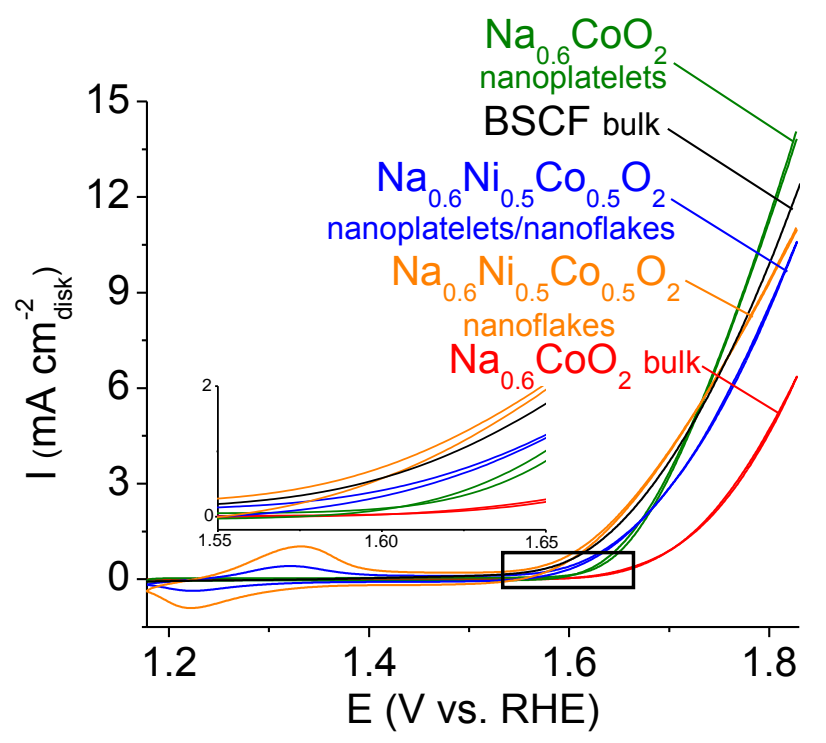

Figure $8.5^{\text {th }}$ linear sweep voltammetry scans $\left(20 \mathrm{mV} \cdot \mathrm{s}^{-1}\right)$ of bulk BSCF (black), bulk $\mathrm{Na}_{0.6} \mathrm{CoO}_{2}$ (red), $\quad \mathrm{Na}_{0.6} \mathrm{CoO}_{2}$ nanoplatelets (green), $\mathrm{Na}_{0.6} \mathrm{Ni}_{0.5} \mathrm{Co}_{0.5} \mathrm{O}_{2}$ mix of nanoplatelets and nanoflakes (blue), $\mathrm{Na}_{0.6} \mathrm{Ni}_{0.5} \mathrm{Co}_{0.5} \mathrm{O}_{2}$ nanoflakes (orange). The inset shows a zoom in of the onset potential area.

Table 3. Overpotentials at current density $5 \mathrm{~mA} \cdot \mathrm{cm}^{-2}$ disk and Tafel analysis parameters retrieved from plots Figure SI.8.

\begin{tabular}{lll}
\hline Sample & $\begin{array}{l}\text { Overpotential at } \\
5 \mathrm{~mA} \cdot \mathrm{cm}^{-2}{ }_{\text {disk }}(\mathrm{mV})\end{array}$ & $\begin{array}{l}\text { Slope } \\
\left(\mathrm{mV} \cdot \mathrm{dec}^{-1}\right)\end{array}$ \\
\hline BSCF bulk & 500 & 58 \\
$\mathrm{Na}_{0.6} \mathrm{CoO}_{2}$ bulk & 580 & 31 \\
$\mathrm{Na}_{0.6} \mathrm{CoO}_{2}$ nanoplatelets & 500 & 29 \\
$\mathrm{Na}_{0.6} \mathrm{CoO}_{2}$ nanoplatelets & & 35 \\
after $5 \mathrm{~h}$ at $5 \mathrm{~mA} \cdot \mathrm{cm}_{\text {disk }}^{-2}$ & 540 & 28 \\
$\mathrm{Na}_{0.6} \mathrm{Ni}_{0.5} \mathrm{Co}_{0.5} \mathrm{O}_{2}$ nanoplatelets/nanoflakes & 520 & 33 \\
$\begin{array}{l}\mathrm{Na}_{0.6} \mathrm{Ni}_{0.5} \mathrm{Co}_{0.5} \mathrm{O}_{2} \text { nanoplatelets/nanoflakes } \\
\text { after } 5 \mathrm{~h} \text { at } 5 \mathrm{~mA}^{-\mathrm{cm}^{-2}} \text { disk }\end{array}$ & 560 & 29 \\
$\mathrm{Na}_{0.6} \mathrm{Ni}_{0.5} \mathrm{Co}_{0.5} \mathrm{O}_{2}$ nanoflakes & 490 &
\end{tabular}


In order to assess the stability of the nanomaterials in operating conditions, chronopotentiometry measurements were performed at a current density of $5 \mathrm{~mA} \mathrm{~cm}{ }^{-2}$ (Figure 9). Every hour, an LSV cycle was recorded. For the three nanostructured materials, the steady state is reached after $\sim 40$ min after each LSV recording, with slight increase in the potential after $5 \mathrm{~h}$. The electrochemical behaviour recorded by LSV every hour is however similar upon time, thus suggesting that the apparent loss of activity, is related to the loss of active matter, presumably by detachment of the nanoparticles from the composite. This is confirmed by the similar Tafel slopes before and after chronopotentiometry (Figure SI.8 and Table S1) at $\sim 30 \mathrm{mV} \cdot \mathrm{dec}^{-1}$ that suggest similar electrocatalytic mechanism, hence showing limited evolution of the electrocatalytic species. According to overpotentials (Table 3), the pure $\mathrm{Na}_{0.6} \mathrm{Ni}_{0.5} \mathrm{Co}_{0.5} \mathrm{O}_{2}$ nanoflakes remain the most active material. Note also that for the $\mathrm{Ni}$ substituted samples, the $\mathrm{Ni}(\mathrm{II}) / \mathrm{Ni}(\mathrm{III})$ wave observed in the first $\mathrm{LSV}$ experiments (Figure 8) disappeared after few hours, thus suggesting structural evolution of the materials. To further assess such evolution in the nanoflakes case, the composite electrode was analyzed by EDX after $6 \mathrm{~h}$ of chronopotentiometry measurement. The $\mathrm{Co} / \mathrm{Ni}$ ratio was maintained, but sodium was lost and replaced by potassium from the electrolyte. Whether potassium becomes part of the catalyst structure or is only sequestered by the ion exchange Nafion polymer is an open question that will be assessed in the near future. All in all, nanoscaling layered cobaltites significantly 
improved their electrocatalytic activity for the OER. Based on the overpotentials, the resulting material reaches electrocatalytic activity comparable to most active materials, like BSCF. The evolution of the chemical composition suggests restructuration of the nanomaterials, but without loss of electrocatalytic activity.
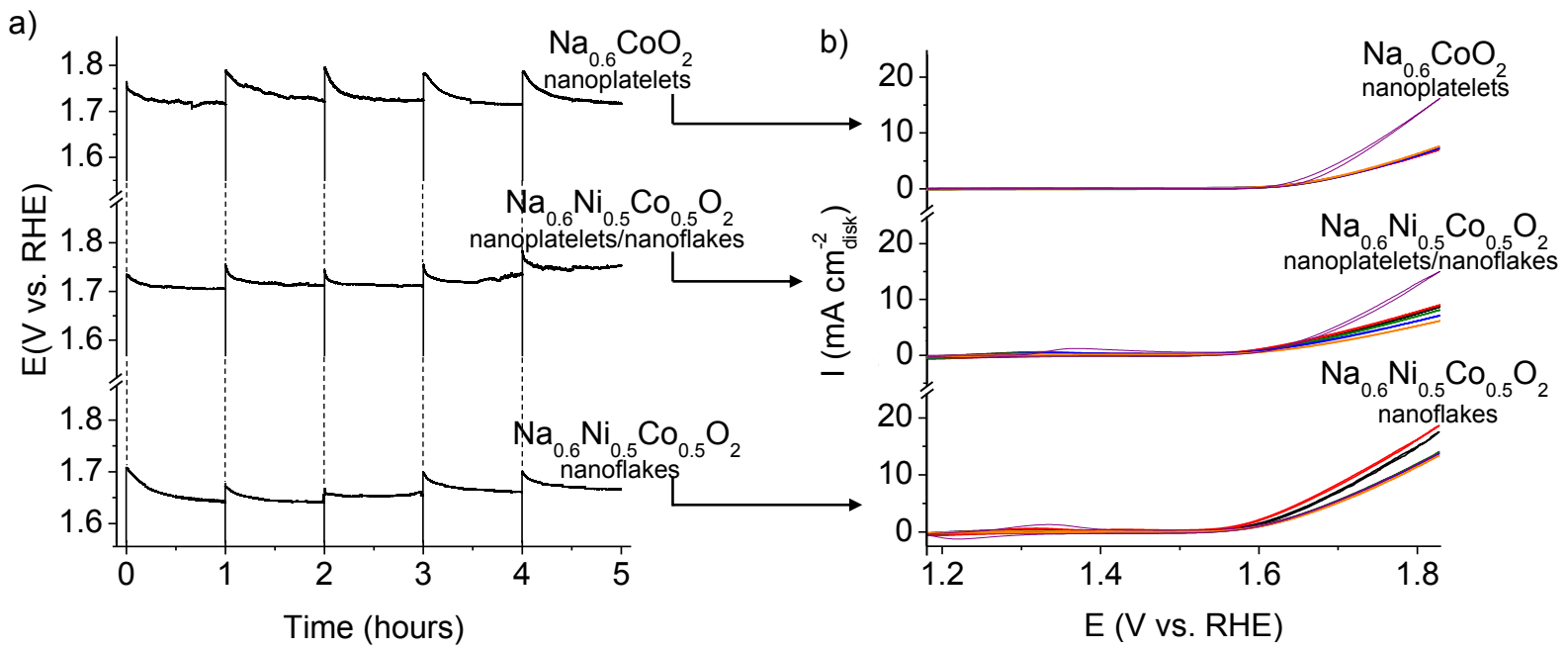

Figure 9. (a) Chronopotentiometry curves at current density $5 \mathrm{~mA} \cdot \mathrm{cm}^{-2}$ of $\mathrm{Na}_{0.6} \mathrm{CoO}_{2}$ medium size, $\mathrm{Na}_{0.6} \mathrm{Ni}_{0.5} \mathrm{Co}_{0.5} \mathrm{O}_{2}$ mix of nanoplatelets and nanoflakes, and $\mathrm{Na}_{0.6} \mathrm{Ni}_{0.5} \mathrm{Co}_{0.5} \mathrm{O}_{2}$ nanoflakes. (b) Linear Sweep Voltammetry curves recorded every hour during the chronopotentiometry measurements for $\mathrm{Na}_{0.6} \mathrm{CoO}_{2}$ nanoplatelets, $\mathrm{Na}_{0.6} \mathrm{Ni}_{0.5} \mathrm{Co}_{0.5} \mathrm{O}_{2}$ mix of nanoplatelets and nanoflakes, and $\mathrm{Na}_{0.6} \mathrm{Ni}_{0.5} \mathrm{Co}_{0.5} \mathrm{O}_{2}$ nanoflakes: 0 (initial, purple), 1 (black), 2 (red), 3 (green), 4 (blue) and 5 (orange) hours.

\section{CONCLUSION}

To conclude, we have developed a synthesis method relying on soft chemistry in water to yield 2 to 5 cobalt oxide layers-thick 2D nanostructures of sodium cobaltite, which can be substituted at will with nickel. The relevance of the approach resides in the ability to preserve high oxidation states $\left(\mathrm{Co}^{3+} / \mathrm{Co}^{4+}\right.$ species $)$, even in few layers-thick $2 \mathrm{D}$ nanomaterials. These new nanomaterials exhibit significantly higher electrocatalytic activity for the oxygen evolution in alkaline aqueous electrolyte than their bulk counterparts and reach activities and performance 
stability comparable to reference materials that are obtained through much harsher synthetic conditions. From a more fundamental viewpoint, this study also shows how, in complex oxides, nanostructures can be used as an additional lever to tune compositional ranges, as they accommodate wider substitution ranges than would larger objects.

\section{ACKNOWLEDGEMENT}

This work was supported by the Spanish Ministry of Innovation, Science and Technology and Spanish Ministry of Economy and Competitiveness through Research Projects CSD2009-00013, TSI-020100-2011-280, MAT2014-52405-C02-01, and MAT2017-82252-R. We thank the National Center of Electron Microscopy (UCM) for facilities. This work was also partly funded by the CNRS, Sorbonne Université, CNRS, and region Ile de France through Domaine d'Intérêt Majeur C'Nano-DIM Nano-K with the COSMOS project.

SUPPORTING INFORMATION. XRD and TEM analyses of a $\mathrm{Na}_{0.6} \mathrm{CoO}_{2}$ sample, TEM and STEM-HAADF images of Ni-doped layered cobaltites, details of STEMHAADF, ABF and EELS characterizations, LSV cycles at different scan rates, Tafel plots.

\section{REFERENCES}

(1) Butler, S. Z.; Hollen, S. M.; Cao, L.; Cui, Y.; Gupta, J. A.; Gutiérrez, H. R.; Heinz, T. F.; Hong, S. S.; Huang, J.; Ismach, A. F.; et al. Progress, Challenges, and Opportunities in Two-Dimensional Materials beyond Graphene. ACS Nano 2013, 7, 2898-2926.

(2) Kalantar-zadeh, K.; Ou, J. Z.; Daeneke, T.; Mitchell, A.; Sasaki, T.; Fuhrer, M. S. 
Two Dimensional and Layered Transition Metal Oxides. Appl. Mater. Today 2016, 5, 73-89.

(3) Viciu, L.; Bos, J. W. G.; Zandbergen, H. W.; Huang, Q.; Foo, M. L.; Ishiwata, S.; Ramirez, A. P.; Lee, M.; Ong, N. P.; Cava, R. J. Crystal Structure and Elementary Properties of $\mathrm{Na}_{\mathrm{x}} \mathrm{CoO}_{2}(\mathrm{x}=0.32,0.51,0.6,0.75$, and 0.92) in the Three-Layer $\mathrm{NaCoO}_{2}$ Family. Phys. Rev. B 2006, 73, 174104.

(4) Whittingham, M. S. Lithium Batteries and Cathode Materials. Chem. Rev., 2004, 104, 4271-4302.

(5) Wang, B.; Bates, J. B.; Hart, F. X.; Sales, B. C.; Zuhr, R. A.; Robertson, J. D. Characterization of Thin-Film Rechargeable Lithium Batteries with Lithium Cobalt Oxide Cathodes. J. Electrochem. Soc. 1996, 143, 3203-3213.

(6) Leifer, N.; Srur-Lavi, O.; Matlahov, I.; Markovsky, B.; Aurbach, D.; Goobes, G. $\mathrm{LiNi}_{0.8} \mathrm{Co}_{0.15} \mathrm{Al}_{0.05} \mathrm{O}_{2}$ Cathode Material: New Insights via ${ }^{7} \mathrm{Li}$ and ${ }^{27} \mathrm{Al}$ MagicAngle Spinning NMR Spectroscopy. Chem. Mater. 2016, 28, 7594-7604.

(7) Ding, J. J.; Zhou, Y. N.; Sun, Q.; Yu, X. Q.; Yang, X. Q.; Fu, Z. W. Electrochemical Properties of P2-Phase $\mathrm{Na}_{0.74} \mathrm{CoO}_{2}$ Compounds as Cathode Material for Rechargeable Sodium-Ion Batteries. Electrochim. Acta 2013, 87, 388-393.

(8) Baster, D.; Dybko, K.; Szot, M.; Świerczek, K.; Molenda, J. Sodium Intercalation in $\mathrm{Na}_{\mathrm{x}} \mathrm{CoO}_{2-\mathrm{y}}$ - Correlation between Crystal Structure, Oxygen Nonstoichiometry and Electrochemical Properties. Solid State Ionics 2014, 262, 206-210.

(9) Takada, K.; Sakurai, H.; Takayama-Muromachi, E.; Izumi, F.; Dilanian, R. A.; Sasaki, T. Superconductivity in Two-Dimensional $\mathrm{CoO}_{2}$ Layers. Nature 2003, 422, 53-55.

(10) Terasaki, I.; Sasago, Y.; Uchinokura, K. Large Thermoelectric Power in $\mathrm{NaCo}_{2} \mathrm{O}_{4}$ Single Crystals. Phys. Rev. B 1997, 56, R12685-R12687.

(11) Douin, M.; Guerlou-Demourgues, L.; Goubault, L.; Bernard, P.; Delmas, C. Evolution Mechanism of the $\mathrm{Na}_{0.6} \mathrm{CoO}_{2}$ Conductive Additive during Cycling in the Alkaline Electrolyte of Ni-MH Batteries. J. Electrochem. Soc. 2009, 156, A459-A467.

(12) Snyder, G. J.; Toberer, E. S. Complex Thermoelectric Materials. Nat. Mater. 2008, 7, 105-114.

(13) Portehault, D.; Maneeratana, V.; Candolfi, C.; Oeschler, N.; Veremchuk, I.; Grin, Y.; Sanchez, C.; Antonietti, M. Facile General Route toward Tunable Magnéli Nanostructures and Their Use as Thermoelectric Metal Oxide / Carbon Nanocomposites. ACS Nano 2011, 5, 9052-9061.

(14) Suntivich, J.; May, K. J.; Gasteiger, H. A.; Goodenough, J. B.; Shao-Horn, Y. A Perovskite Oxide Optimized for Oxygen Evolution Catalysis from Molecular Orbital Principles. Science 2011, 334, 1383-1385.

(15) Grimaud, A.; May, K. J.; Carlton, C. E.; Lee, Y.-L.; Risch, M.; Hong, W. T.; Zhou, J.; Shao-Horn, Y. Double Perovskites as a Family of Highly Active Catalysts for Oxygen Evolution in Alkaline Solution. Nat. Commun. 2013, 4, 2439.

(16) Bergmann, A.; Martinez-Moreno, E.; Teschner, D.; Chernev, P.; Gliech, M.; de Araújo, J. F.; Reier, T.; Dau, H.; Strasser, P. Reversible Amorphization and the Catalytically Active State of Crystalline $\mathrm{Co}_{3} \mathrm{O}_{4}$ during Oxygen Evolution. Nat . Commun. 2015, 6, 8625.

(17) Abidat, I.; Morais, C.; Comminges, C.; Canaff, C.; Rousseau, J.; Guignard, N.; Napporn, T. W.; Habrioux, A.; Kokoh, K. B. Three Dimensionally Ordered Mesoporous Hydroxylated $\mathrm{Ni}_{\mathrm{x}} \mathrm{Co}_{3-\mathrm{x}} \mathrm{O}_{4}$ Spinels for the Oxygen Evolution 
Reaction: On the Hydroxyl-Induced Surface Restructuring Effect. J. Mater. Chem. A 2017, 5, 7173-7183.

(18) Suen, N.-T.; Hung, S.-F.; Quan, Q.; Zhang, N.; Xu, Y.-J.; Chen, H. M. Electrocatalysis for the Oxygen Evolution Reaction: Recent Development and Future Perspectives. Chem. Soc. Rev. 2017, 46, 337-365.

(19) Chen, Z.; Kronawitter, C. X.; Waluyo, I.; Koel, B. E. Investigation of Water Dissociation and Surface Hydroxyl Stability on Pure and Ni-Modified CoOOH by Ambient Pressure Photoelectron Spectroscopy. J. Phys. Chem. B 2018, 810817.

(20) Chen, Z.; Kronawitter, C. X.; Yeh, Y.-W.; Yang, X.; Zhao, P.; Yao, N.; Koel, B. E. Activity of Pure and Transition Metal-Modified $\mathrm{CoOOH}$ for the Oxygen Evolution Reaction in an Alkaline Medium. J. Mater. Chem. A 2017, 5, 842-850.

(21) Levi, E.; Aurbach, D. Lattice Strains in the Layered Mn, Ni and Co Oxides as Cathode Materials in Li and Na Batteries. Solid State Ionics 2014, 264, 54-68.

(22) Doubaji, S.; Valvo, M.; Saadoune, I.; Dahbi, M.; Edström, K. Synthesis and Characterization of a New Layered Cathode Material for Sodium Ion Batteries. $J$. Power Sources 2014, 266, 275-281.

(23) Besselink, R.; Stawski, T. M.; Castricum, H. L.; Blank, D. H. A.; ten Elshof, J. E. Exfoliation and Restacking of Lepidocrocite-Type Layered Titanates Studied by Small-Angle X-Ray Scattering. J. Phys. Chem. C 2010, 114, 21281-21286.

(24) Schaak, R. E.; Mallouk, T. E. Prying Apart Ruddlesden-Popper Phases: Exfoliation into Sheets and Nanotubes for Assembly of Perovskite Thin Films. Chem. Mater., 2000, 12, 3427-3434.

(25) Yoshitomo Omomo; Sasaki, T.; Wang, L.; Watanabe, M. Redoxable Nanosheet Crystallites of $\mathrm{MnO}_{2}$ Derived via Delamination of a Layered Manganese Oxide. J. Am. Chem. Soc., 2003, 125, 3568-3575.

(26) Manna, K.; Huang, H.-N.; Li, W.-T.; Ho, Y.-H.; Chiang, W.-H. Toward Understanding the Efficient Exfoliation of Layered Materials by Water-Assisted Cosolvent Liquid-Phase Exfoliation. Chem. Mater. 2016, 28, 7586-7593.

(27) Masuda, Y.; Hamada, Y.; Seo, W. S.; Koumoto, K. Exfoliation of Layers in $\mathrm{Na}_{\mathrm{x}} \mathrm{CoO}_{2}$. J. Nanosci. Nanotechnol. 2006, 6, 1632-1638.

(28) Mikami, M.; Yoshimura, M.; Mori, Y.; Sasaki, T.; Funahashi, R.; Matsubara, I. Crystal Growth of Thermoelectric Material $\mathrm{Na}_{\mathrm{x}} \mathrm{CoO}_{2-\delta}$ by a Flux Method. Jpn. J. Appl. Phys. 2002, 41, L777-L779.

(29) Miclau, M.; Bokinala, K.; Miclau, N. Low-Temperature Hydrothermal Synthesis of the Three-Layered Sodium Cobaltite $\mathrm{P} 3-\mathrm{Na}_{\mathrm{x}} \mathrm{CoO}_{2}(\mathrm{x} \sim 0.60)$. Mater. Res. Bull. 2014, 54, 1-5.

(30) Pétrissans, X.; Bétard, A.; Giaume, D.; Barboux, P.; Dunn, B.; Sicard, L.; Piquemal, J.-Y. Solution Synthesis of Nanometric Layered Cobalt Oxides for Electrochemical Applications. Electrochim. Acta 2012, 66, 306-312.

(31) Sakai, N.; Fukuda, K.; Ma, R.; Sasaki, T. Synthesis and Substitution Chemistry of Redox-Active Manganese/Cobalt Oxide Nanosheets. Chem. Mater. 2018, 30, 1517-1523.

(32) Chivot, J.; Mendoza, L.; Mansour, C.; Pauporté, T.; Cassir, M. New Insight in the Behaviour of $\mathrm{Co}-\mathrm{H} 2 \mathrm{O}$ System at $25-150{ }^{\circ} \mathrm{C}$, Based on Revised Pourbaix Diagrams. Corros. Sci. 2008, 50, 62-69.

(33) Stephen, H.; Stephen, T. Solubilities of Inorganic and Organic Compounds, Vol 1, Part 1; New York, 1963.

(34) Pinho, S. P.; Macedo, E. A. Solubility of $\mathrm{NaCl}, \mathrm{NaBr}$, and $\mathrm{KCl}$ in Water, Methanol, Ethanol, and Their Mixed Solvents. J. Chem. Eng. Data, 2005, 50, 29- 
32.

(35) Ellingboe, J. L.; Runnels, J. H. Solubilities of Sodium Carbonate and Sodium Bicarbonate in Acetone-Water and Methanol-Water Mixtures. J. Chem. Eng. Data 1966, 11, 323-324.

(36) Hojo, H.; Mizoguchi, T.; Ohta, H.; Findlay, S. D.; Shibata, N.; Yamamoto, T.; Ikuhara, Y. Atomic Structure of a $\mathrm{CeO}_{2}$ Grain Boundary: The Role of Oxygen Vacancies. Nano Lett. 2010, 10, 4668-4672.

(37) Lee, S.; Oshima, Y.; Sawada, H.; Hosokawa, F.; Okunishi, E.; Kaneyama, T.; Kondo, Y.; Niitaka, S.; Takagi, H.; Tanishiro, Y.; et al. Counting Lithium Ions in the Diffusion Channel of an $\mathrm{LiV}_{2} \mathrm{O}_{4}$ Crystal. J. Appl. Phys. 2011, 109, 113530.

(38) Pearson, D. H.; Ahn, C. C.; Fultz, B. White Lines and $d$-Electron Occupancies for the $3 d$ and $4 d$ Transition Metals. Phys. Rev. B 1993, 47, 8471-8478.

(39) Wang, Z. L.; Yin, J. S. Cobalt Valence and Crystal Structure of $\mathrm{La}_{0.5} \mathrm{Sr}_{0.5} \mathrm{CoO}_{2.25}$. Philos. Mag. B 1998, 77, 49-65.

(40) Wang, Z. L.; Bentley, J.; Evans, N. D. Valence State Mapping of Cobalt and Manganese Using Near-Edge Fine Structures. Micron 2000, 31, 355-362.

(41) Shannon, R. D.; IUCr. Revised Effective Ionic Radii and Systematic Studies of Interatomic Distances in Halides and Chalcogenides. Acta Crystallogr. Sect. A 1976, 32, 751-767.

(42) Wang, F.; Han, Y.; Lim, C. S.; Lu, Y.; Wang, J.; Xu, J.; Chen, H.; Zhang, C.; Hong, M.; Liu, X. Simultaneous Phase and Size Control of Upconversion Nanocrystals through Lanthanide Doping. Nature 2010, 463, 1061-1065.

(43) Trotochaud, L.; Ranney, J. K.; Williams, K. N.; Boettcher, S. W. Solution-Cast Metal Oxide Thin Film Electrocatalysts for Oxygen Evolution. J. Am. Chem. Soc. 2012, 134, 17253-17261.

(44) Shinagawa, T.; Garcia-Esparza, A. T.; Takanabe, K. Insight on Tafel Slopes from a Microkinetic Analysis of Aqueous Electrocatalysis for Energy Conversion. Sci. Rep. 2015, 5, 1-21. 


\title{
Supporting Information
}

\section{Nickel-Doped Sodium Cobaltite 2D Nanomaterials: Synthesis and Electrocatalytic Properties}

\author{
Alberto Azor ${ }^{1}$, Maria Luisa Ruiz-Gonzalez ${ }^{1}$, Francisco Gonell ${ }^{2}$, Christel Laberty- \\ Robert $^{2}$, Marina Parras ${ }^{1}$, Clément Sanchez ${ }^{2}$, David Portehault ${ }^{2, *}$, José M. González- \\ Calbet $^{1, *}$ \\ ${ }^{1}$ Departamento de Química Inorgánica, Facultad de Químicas, Universidad \\ Complutense, 28040-Madrid, Spain \\ ${ }^{2}$ Sorbonne Université, CNRS, Collège de France, PSL Research University, Laboratoire \\ de Chimie de la Matière Condensée de Paris (CMCP), 4 place Jussieu, F-75005, Paris, \\ France
}




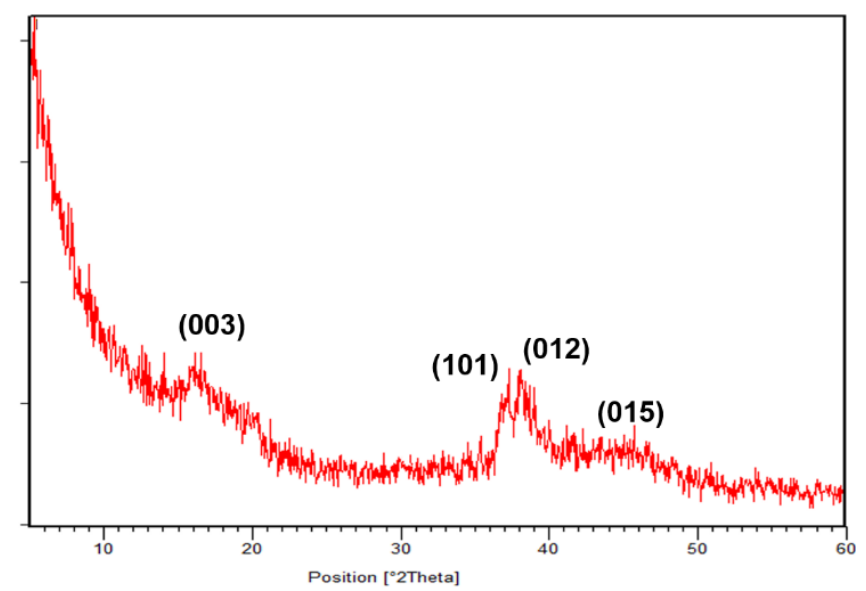

Figure SI.1. $\mathrm{Na}_{\mathrm{x}} \mathrm{Co}_{0.5} \mathrm{Ni}_{0.5} \mathrm{O}_{2} \mathrm{XRD}$ pattern indexed as $\mathrm{Na}_{0.6} \mathrm{CoO}_{2}(\mathrm{C} 2 / \mathrm{m})$. Note that the bad signal-to-noise ratio originates from the fluorescence of cobalt and the emission wavelength of the copper anode of the XRD apparatus.
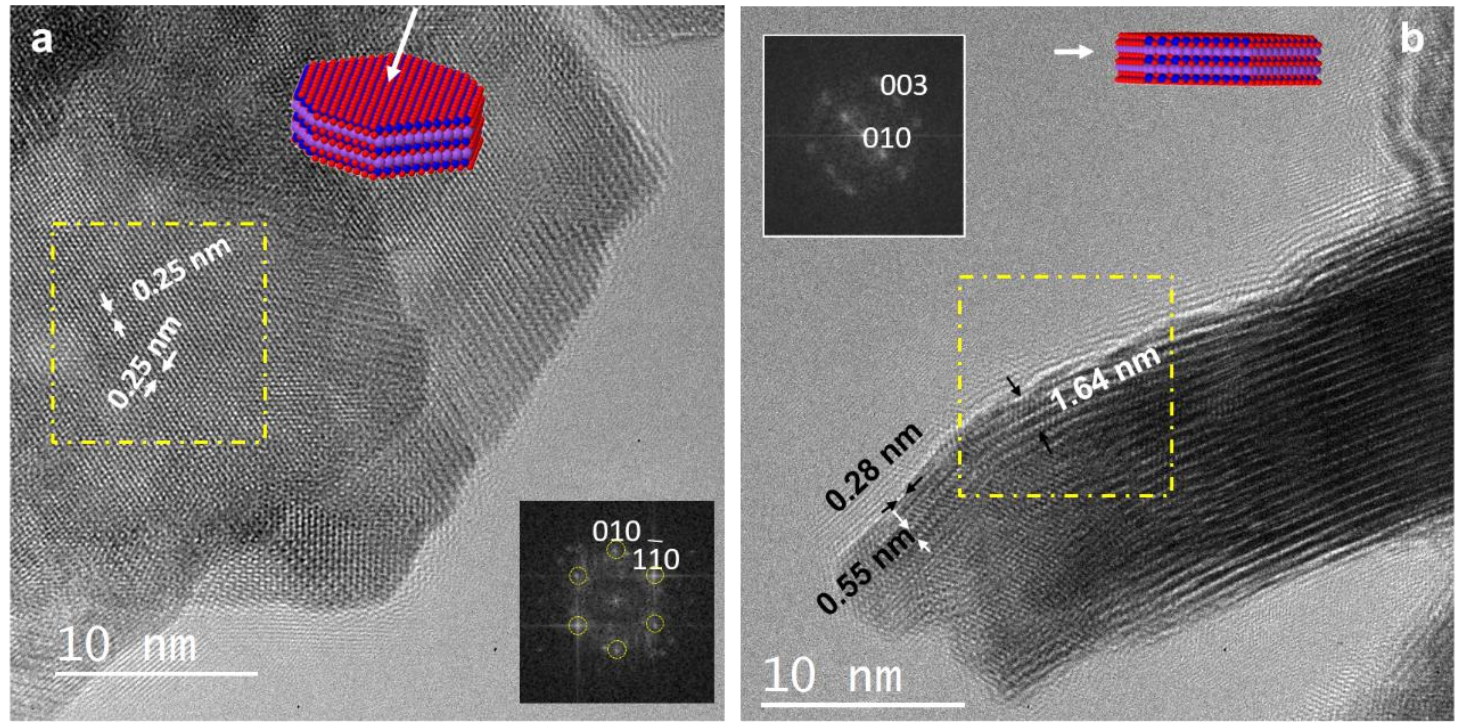

Figure SI.2. HRTEM images of a $\mathrm{Na}_{0.6} \mathrm{CoO}_{2}$ sample. (a) Nanoplatelets oriented along [001] and corresponding FFT of the highlighted area. (b) Nanoplatelet oriented along [100] and corresponding FFT of the highlighted area. 


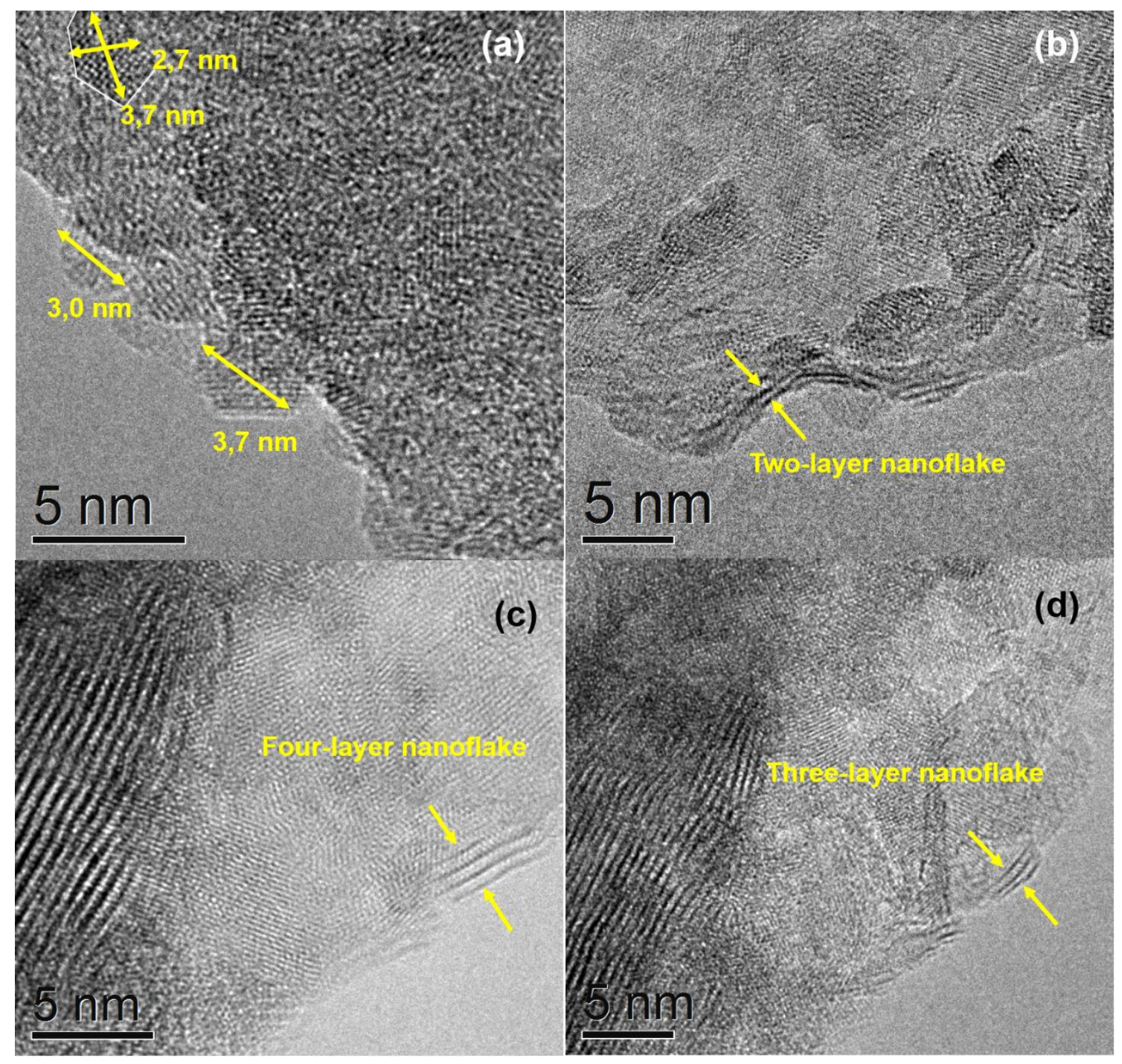

Figure SI.3. HRTEM images of a $\mathrm{Na}_{\mathrm{x}} \mathrm{Ni}_{0.3} \mathrm{Co}_{0.7} \mathrm{O}_{2}$ sample: small particles orientated along two directions: (a) the [001] projection (zone axis). (b-d) the [100] projection (zone axis) of the lamellar $\mathrm{Na}_{\mathrm{x}} \mathrm{CoO}_{2}$ system. 

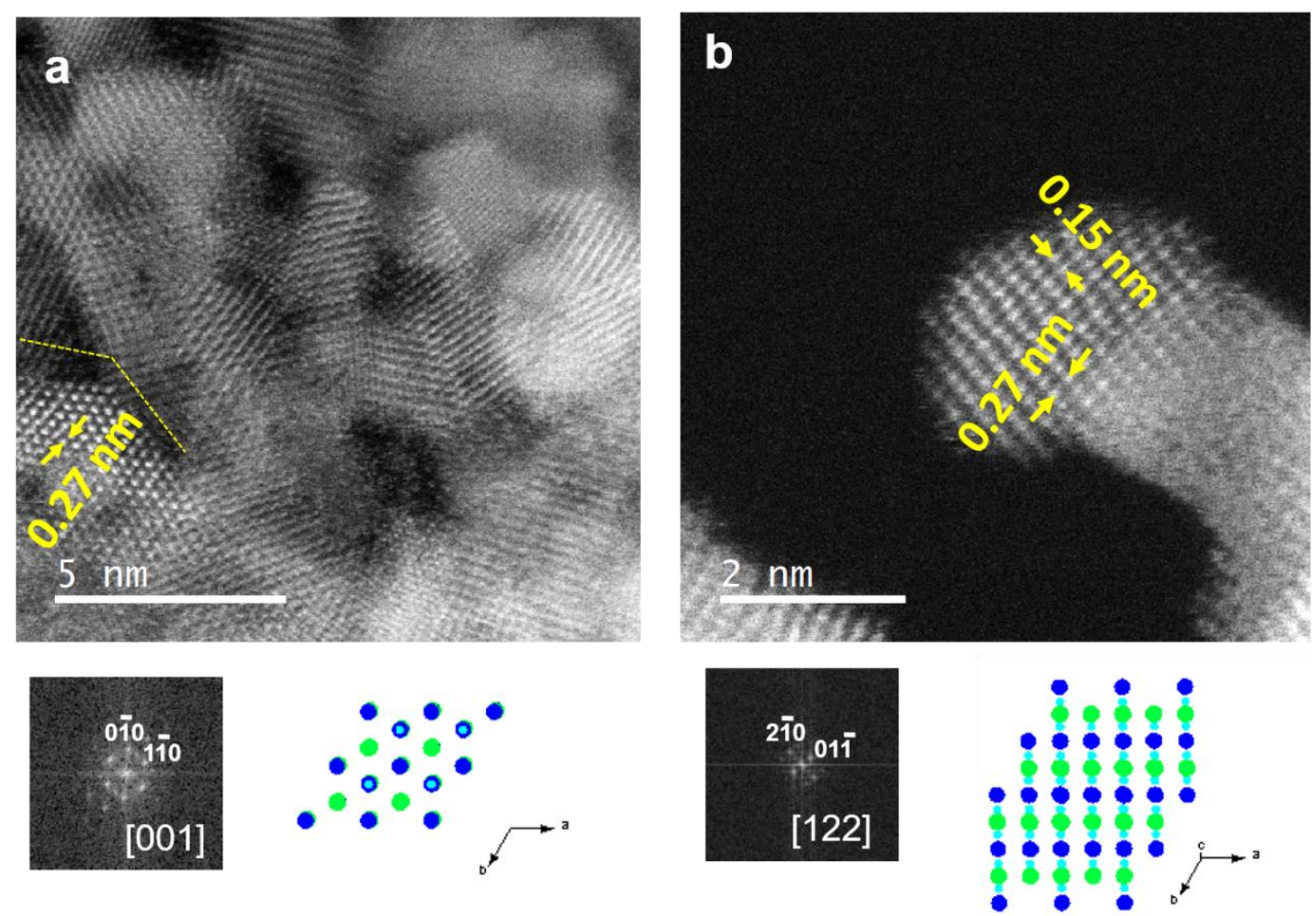

Figure SI.4. (a) HAADF image of a group of nanoflakes representative of a sample $\mathrm{Na}_{0.6} \mathrm{Ni}_{0.5} \mathrm{Co}_{0.5} \mathrm{O}_{2}$ as well as the FFT of the highlighted area and its structural model. (b) HAADF image of an isolated nanoflake oriented along the [122] direction with its FFT and the structural model along that direction.

\section{SI.A Atomically resolved characterization: STEM-HAADF, ABF and EELS}

In order to get further structural and compositional information about the cation and anion distribution as well as the $\mathrm{Co}$ and $\mathrm{Ni}$ oxidation state, an atomically resolved study was performed. An aberration-corrected Scanning Transmission Electron Microscope (STEM) JEOL JSM-ARM200cF microscope (Cold Emission Gun) was used with two different imaging techniques in STEM mode: HAADF (high annular angle dark field) and ABF (annular bright field). In addition, local compositional analysis was performed through the acquisition of either EELS spectrum images in 2D areas (in order to get chemical maps to determine the cation distribution) or EELS spectrum lines (for Co and $\mathrm{Ni}=$ oxidation state determination) of constant thickness. The relative thickness has been calculated from low loss spectrum by comparison to the inelastic signal applying Poisson statistics. The voltage was set to $80 \mathrm{kV}$ in order to minimize the electron beam damage. EELS data have been acquired using a GIF Quantum ER spectrometer which comprises a lenses system able to correct fifth order aberration allowing high collection angles $(>100 \mathrm{eV})$ with energy resolution close to $0.1 \mathrm{eV}$ 
HAADF implies the collection of the electrons scattered at high angles (Solid semiangles between 68-280 mrad) resulting in incoherent imaging. Under these experimental conditions, the scattered intensity is approximately proportional to $\mathrm{Z}^{1.83}$ ( $\mathrm{Z}=$ atomic number of the elements in the sample). In this sense, the intensity differences among columns must be related to the different cationic composition and therefore, HAADF provides images for which contrast can be qualitative interpreted as chemical information: the brighter contrast would correspond to heaviest elements while less bright contrast to those elements with lower Z. The incorporation of spherical aberration correctors allows acquiring HAADF images with atomic resolution, making possible to resolve and locate cationic columns with different atomic number if the difference is around 20 units. In our case since $\mathrm{Co}(\mathrm{Z}=27)$ and $\mathrm{Ni}(\mathrm{Z}=28)$ only differ in one unit, the HAADF does not provide information of their distribution that means if whether or not they are randomly or ordered on the corresponding atomic columns. To resolve this target atomically resolved EELS spectrum-images are required.

On the other hand, using HAADF experimental conditions, the light elements such as oxygen are barely visible, especially when heavy elements are present. In ABF imaging, the collection angle is modified (11-22 mrad) to enhance the contrast of the lighter elements. The required system in the JEOL-JEM ARM200 microscope consists on a bright field detector in which the central area is blanked with a beam stopper providing an annular detector. By modifying the camera length, the appropriate solid angle to enhance the contrast of the oxygen atomic columns is optimized. The resulting image allows the visualization of both light and heavy atomic columns. Opposite to HAADF the atoms are seen in grey scale. Acquisition times of $38 \mathrm{~s}$ per frame were used for HAADF and ABF images.

\section{EELS analysis}

The convergence and collection semi-angles used were 18 and $20.3 \mathrm{mrad}$, respectively.

\section{Chemical maps}

To enable simultaneous analysis of $\mathrm{O}-\mathrm{K}(532 \mathrm{eV}), \mathrm{Co}-\mathrm{L}_{2,3}(779 \mathrm{eV}), \mathrm{Ni}-\mathrm{L}_{2,3}(8505 \mathrm{eV})$, and $\mathrm{Na}-\mathrm{K}(1072 \mathrm{eV})$ edges, an spectrum imaging (30 x 19 spectra) was recorded by using a dispersion of $0.5 \mathrm{eV}$ per channel. The chemical maps were obtained by 
analyzing every individual spectra of the $\mathrm{O}-\mathrm{K}(532 \mathrm{eV}), \mathrm{Co}-\mathrm{L}_{2,3}(779 \mathrm{eV}), \mathrm{Ni}-\mathrm{L}_{2,3}(8505$ $\mathrm{eV})$, and $\mathrm{Na}-\mathrm{K}(1072 \mathrm{eV})$ signals in the sum spectra. Principal Component Analysis (Bonnet, N.; Brun, N.; Colliex, C. Ultramicroscopy 1999, 77, 97) was performed on EELS data set to de-noise the spectra by using the PCA routines for Diginal Micrograph (M. Bosman, M. Watanabe, D. T. L. Alexander, V. J. Keast, Ultramicroscopy 2006, 106, 1024). A power-law background subtraction was used for the selected spectrum and all the edge setup applied to the parent spectrum imaging.

\section{Cobalt and nickel oxidation state study}

EELS spectrum lines were acquired for $\mathrm{Co}$ and $\mathrm{Ni}$ oxidation state determination. The scanning of the beam position over a line in the particles during short times allows the spectra acquisition minimizing the sample damage. An average of 220 spectra were acquired along lines about $2 \mathrm{~nm}$ long, during a total acquisition time of 30 seconds. The energy dispersion was set to $0.25 \mathrm{eV}$. The $\mathrm{Co}_{3,2}$-edges are displayed Figure SI.5.

In order to get information about the cobalt oxidation state, the intensity ratio between the $\mathrm{L}_{3}$ and $\mathrm{L}_{2}$ lines was first determined and compared with the values measured for standards $\left.\mathrm{CoO}(\mathrm{Co}(\mathrm{II})), \mathrm{LaCoO}_{3}(\mathrm{CoIII})\right)$ and reported for the standard $\mathrm{CoSi}_{2}(\mathrm{Co}(\mathrm{IV}))$ by Wang et al. (Wang, Z. L.; Yin, J. S. Cobalt Valence and Crystal Structure of $\mathrm{La}_{0.5} \mathrm{Sr}_{0.5} \mathrm{CoO}_{2.25}$. Philos. Mag. B 1998, 77, 49-65 Wang, Z. L.; Bentley, J.; Evans, N. D. Valence State Mapping of Cobalt and Manganese Using near-Edge Fine Structures. Micron 2000, 31, 355-362). The white lines $\mathrm{L}_{3} / \mathrm{L}_{2}$ ratios measured over 15 areas were 2.5( \pm 0.1$)$ and 2.6( \pm 0.1$)$ for undoped and Ni-doped samples, respectively. These similar values suggest close average oxidation state between these three samples. The corresponding intensity ratios for the experimental $\mathrm{Co}(\mathrm{III})$ and $\mathrm{Co}(\mathrm{II})$ standards are 2.7( \pm 0.1$)$ and $4.4( \pm 0.1)$ for $\mathrm{LaCoO}_{3}$ and $\mathrm{CoO}$, respectively, in agreement with the $\mathrm{L}_{3} / \mathrm{L}_{2}$ plot versus the oxidation state drawn by Wang et al. Accordingly, the undoped and Ni-doped samples present a mixed valence $\mathrm{Co}(\mathrm{III}) / \mathrm{Co}(\mathrm{IV})$.

Note that in the absence of $\mathrm{CoSi}_{2}$, we have assessed $\mathrm{Ba}_{2} \mathrm{CoO}_{4}$ as another $\mathrm{Co}$ (IV) standard. However, partial overlapping of Co-L $\mathrm{L}_{3,2}$ signals $\left(\mathrm{Co}_{-} \mathrm{L}_{3} \sim 779 \mathrm{eV}\right.$; Co$\left.\mathrm{L}_{2} \sim 794 \mathrm{eV}\right)$ with the more intense edge of Ba-M $\mathrm{M}_{4,5}\left(\mathrm{Ba}-\mathrm{M}_{5} \sim 781 \mathrm{eV} ; \mathrm{Ba}-\mathrm{M}_{4} \sim 796 \mathrm{eV}\right)$ in $\mathrm{Ba}_{2} \mathrm{CoO}_{4}$ hinders precise evaluation of the $\mathrm{Co}-\mathrm{L}_{3} / \mathrm{L}_{2}$ intensity ratio, so that the reference $\mathrm{CoSi}_{2}$ reported by Wang et al. was used.

In order to confirm the mixed valence $\mathrm{Co}(\mathrm{IV}) / \mathrm{Co}(\mathrm{III})$, we have evaluated the 
energy shift of the Co- $\mathrm{L}_{2,3}$ edges of the doped and undoped samples in comparison with the reference oxides measured in this sample: $\mathrm{Ba}_{2} \mathrm{CoO}_{4}$ for $\mathrm{Co}$ (IV) (suitable for evaluation of energy shifts rather than the $\mathrm{L}_{3} / \mathrm{L}_{2}$ ratio discussed above), $\mathrm{LaCoO}_{3}$ for $\mathrm{Co}(\mathrm{III})$ and $\mathrm{CoO}$ for $\mathrm{Co}(\mathrm{II})$. Comparison with the standards in Figure SI.5a-c show that the $\mathrm{Co}_{-} \mathrm{L}_{3,2}$ edges of either doped and undoped samples, appear between shifted to higher energy loss values those of $\mathrm{LaCoO}_{3}$ and of $\mathrm{Ba}_{2} \mathrm{CoO}_{4}$, thus confirming mixed valence $\mathrm{Co}(\mathrm{IV}) / \mathrm{Co}(\mathrm{III})$ with no $\mathrm{Co}(\mathrm{II})$. Figures SI.5d and e confirm this statement with comparison with a known $\mathrm{Co}(\mathrm{IV}) / \mathrm{Co}(\mathrm{III}) \mathrm{La}_{0.7} \mathrm{Sr}_{0.3} \mathrm{CoO}_{3}$ perovskite standard.
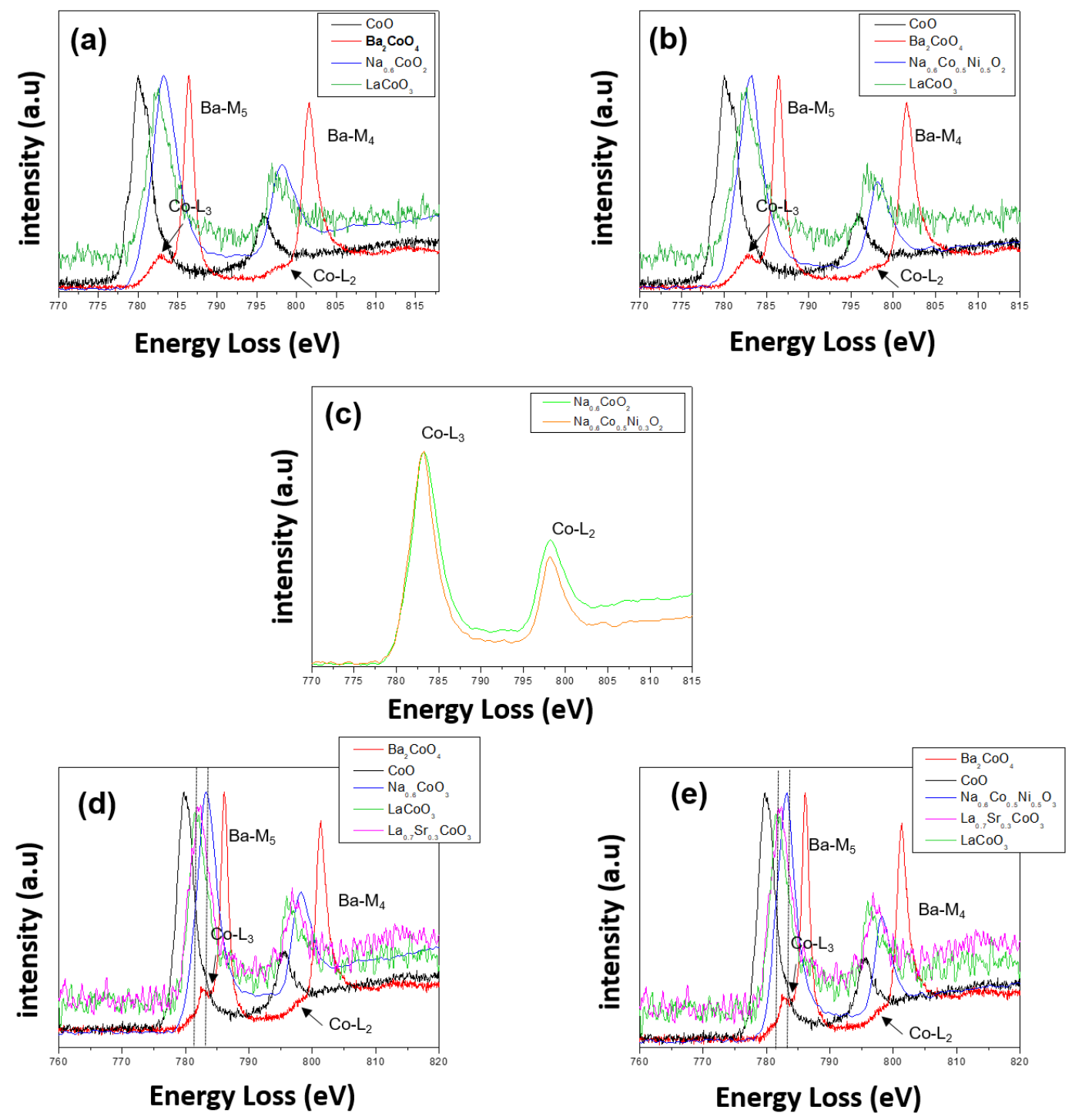

Figure SI.5. (a) EELS spectra showing the Co- $\mathrm{L}_{2,3}$ edge of $\mathrm{Na}_{0.6} \mathrm{CoO}_{2}$ in comparison with standards: $\mathrm{CoO}, \mathrm{LaCoO}_{3}$ and $\mathrm{Ba}_{2} \mathrm{CoO}_{4}$; (b) EELS spectra showing the $\mathrm{Co}-\mathrm{L}_{2,3}$ edge of $\mathrm{Na}_{0.6} \mathrm{Co}_{0.5} \mathrm{Ni}_{0.5} \mathrm{O}_{2}$ in comparison with standards $\mathrm{CoO}, \mathrm{LaCoO}_{3}$ and $\mathrm{Ba}_{2} \mathrm{CoO}_{4}$; (c) Co$\mathrm{L}_{2,3}$ edges of $\mathrm{Na}_{0.6} \mathrm{CoO}_{2}$ and $\mathrm{Na}_{0.6} \mathrm{Co}_{0.5} \mathrm{Ni}_{0.5} \mathrm{O}_{2}$; (d) EELS spectra showing the Co- $\mathrm{L}_{2,3}$ 
edge of $\mathrm{Na}_{0.6} \mathrm{CoO}_{2}$ in comparison with standards: $\mathrm{CoO}, \mathrm{LaCoO}_{3}, \mathrm{Ba}_{2} \mathrm{CoO}_{4}$ and $\mathrm{La}_{0.7} \mathrm{Sr}_{0.3} \mathrm{CoO}_{3}$; (e) EELS spectra showing the Co-L $\mathrm{L}_{2,3}$ edge of $\mathrm{Na}_{0.6} \mathrm{CoO}_{2}$ in comparison with standards: $\mathrm{CoO}, \mathrm{LaCoO}_{3}, \mathrm{Ba}_{2} \mathrm{CoO}_{4}$ and $\mathrm{La}_{0.7} \mathrm{Sr}_{0.3} \mathrm{CoO}_{3}$. Lines have been included as guides for clearness. 
OER electrocatalytic properties

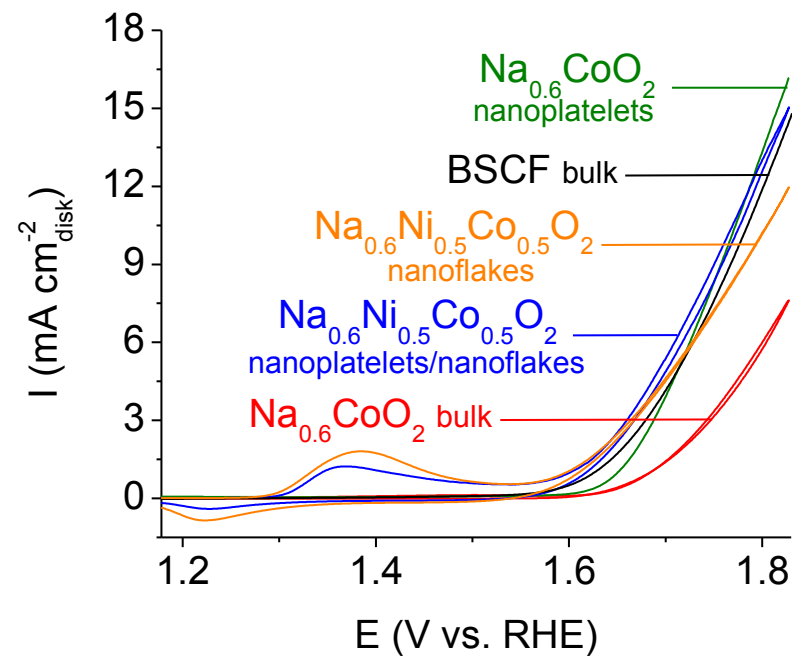

Figure SI.6. First linear sweep voltammetry scans $\left(20 \mathrm{mV} \cdot \mathrm{s}^{-1}\right)$ of bulk BSCF (black), bulk $\mathrm{Na}_{0.6} \mathrm{CoO}_{2}$ (red), $\mathrm{Na}_{0.6} \mathrm{CoO}_{2}$ nanoplatelets (green), $\mathrm{NaNi}_{0.5} \mathrm{Co}_{0.5} \mathrm{O}_{2}$ mix of nanoplatelets and nanoflakes (blue), $\mathrm{NaNi}_{0.5} \mathrm{Co}_{0.5} \mathrm{O}_{2}$ nanoflakes (orange). 

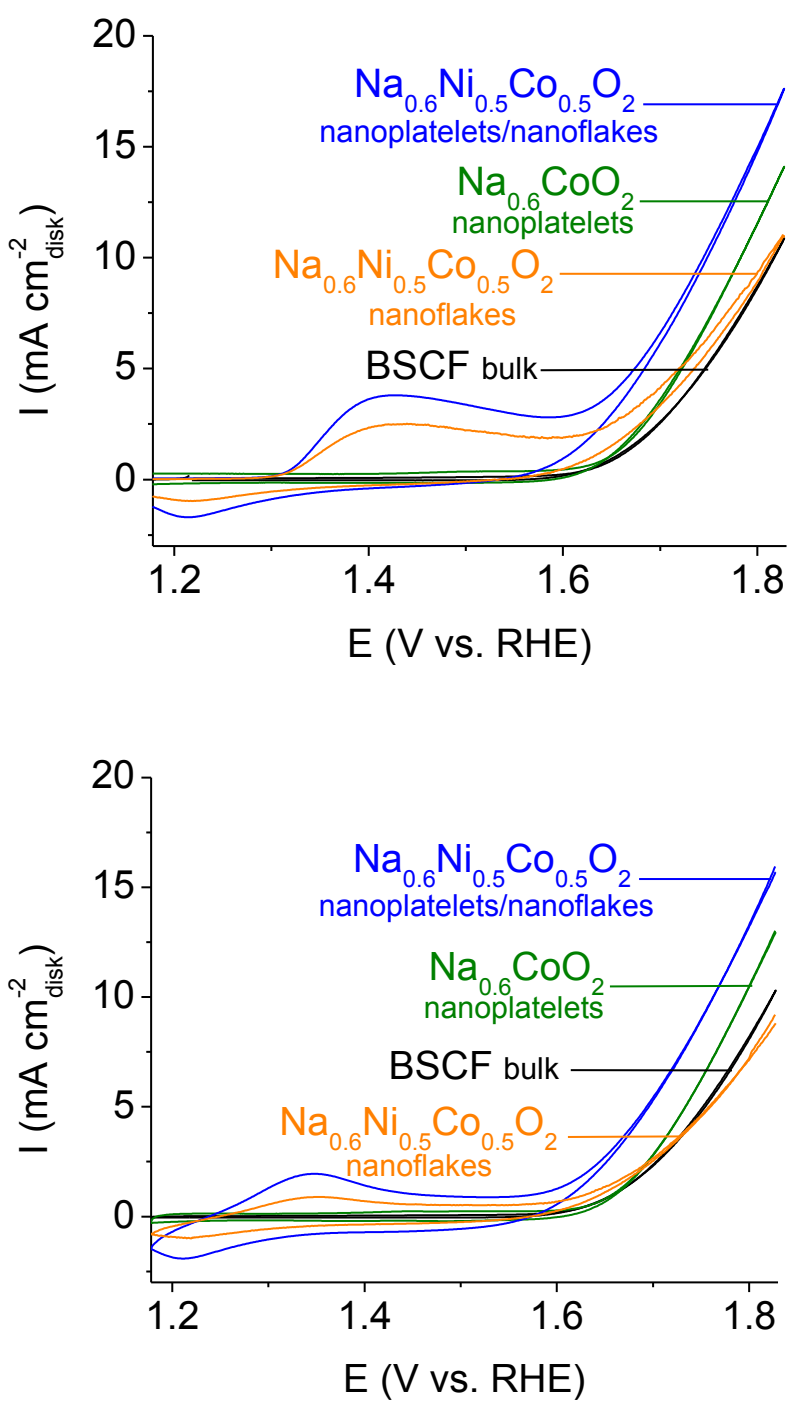

Figure SI.7. $\mathbf{1}^{\text {st }}\left(\right.$ top) and $\mathbf{5}^{\text {th }}\left(\right.$ down) linear sweep voltammetry scans $\left(100 \mathrm{mV} \cdot \mathrm{s}^{-1}\right)$ of bulk BSCF (black), bulk $\mathrm{Na}_{0.6} \mathrm{CoO}_{2}$ (red), $\mathrm{Na}_{0.6} \mathrm{CoO}_{2}$ nanoplatelets (green), $\mathrm{NaNi}_{0.5} \mathrm{Co}_{0.5} \mathrm{O}_{2}$ mix of nanoplatets and nanoflakes (blue), $\mathrm{NaNi}_{0.5} \mathrm{Co}_{0.5} \mathrm{O}_{2}$ nanoflakes (orange). 

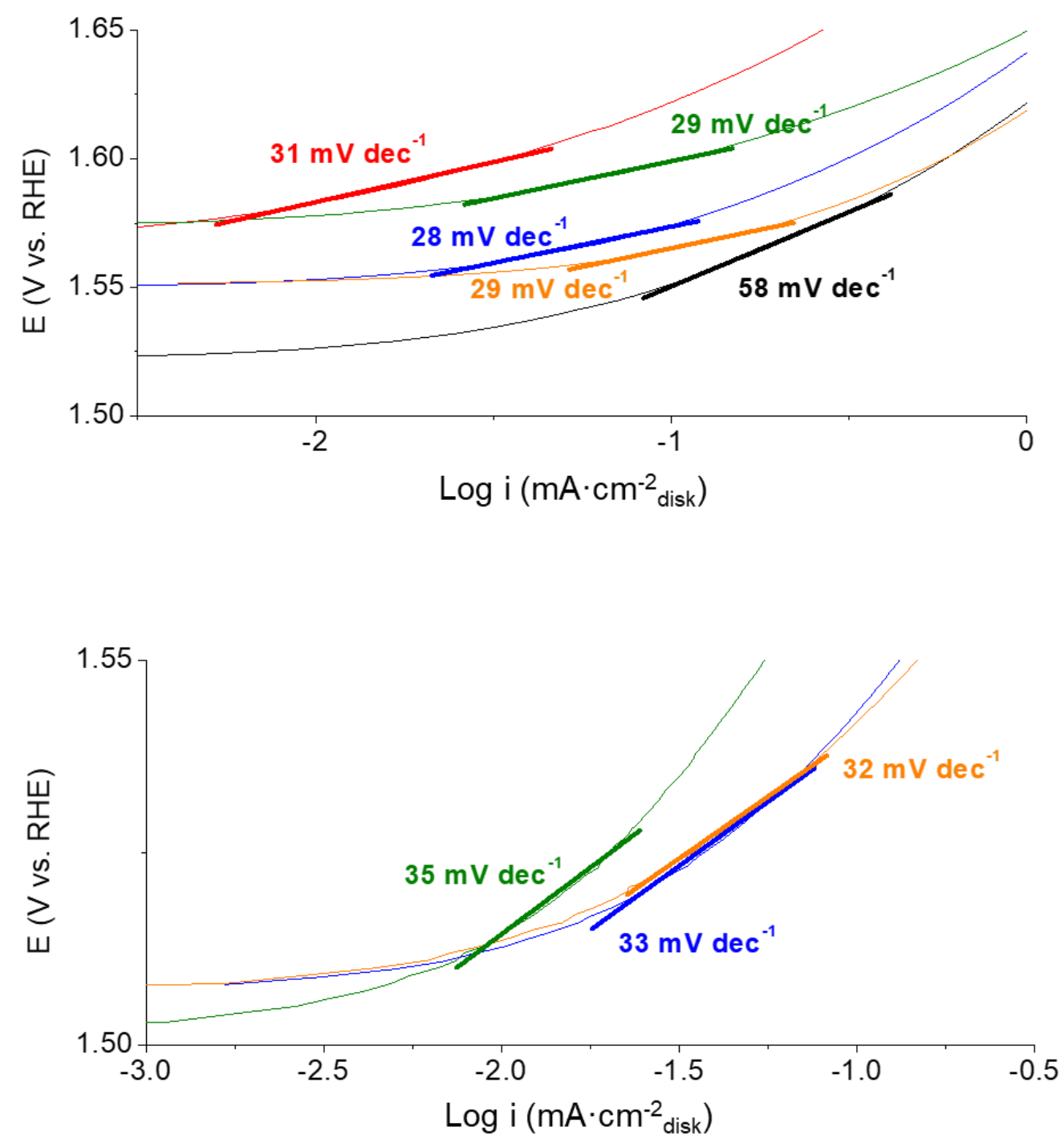

Figure SI.8. Tafel plots at the $5^{\text {th }}$ linear sweep voltammetry scan (top, $20 \mathrm{mV} \cdot \mathrm{s}^{-1}$ ) and after $5 \mathrm{~h}$ chronopotentiometry (bottom, $5 \mathrm{~mA} \cdot \mathrm{cm}^{-2}$ ) of bulk $\mathrm{Na}_{0.6} \mathrm{CoO}_{2}$ (red), $\mathrm{Na}_{0.6} \mathrm{CoO}_{2}$ nanoplatelets (green), $\mathrm{NaNi}_{0.5} \mathrm{Co}_{0.5} \mathrm{O}_{2}$ mix of nanoplatelets and nanoflakes (blue), $\mathrm{NaNi}_{0.5} \mathrm{Co}_{0.5} \mathrm{O}_{2}$ nanoflakes (orange). 